\title{
Polynuclear Photocatalysts in Nanoporous Silica for Artificial Photosynthesis
}

\author{
Heinz Frei*
}

\begin{abstract}
In this article, recent progress towards robust photocatalysts for the visible light-driven reduction of $\mathrm{CO}_{2}$ by $\mathrm{H}_{2} \mathrm{O}$ is presented. All-inorganic polynuclear photocatalysts consisting of an oxo-bridged binuclear chargetransfer chromophore (metal-to-metal charge-transfer) coupled to a multi-electron transfer catalyst anchored in a nanoporous silica scaffold have been developed. Mild synthetic methods afford assembly, on silica nanopore surfaces, of heterobinuclear units with donor and acceptor metal centers selected for optimum solar coverage and photon to chemical energy conversion efficiency. A photocatalyst featuring a TiOCrll group coupled to an $\mathrm{IrO}_{2}$ nanocluster on MCM-41 silica support is shown to function as an efficient visible light water oxidation unit. Nanostructured $\mathrm{Co}_{3} \mathrm{O}_{4}$ clusters in mesoporous silica SBA-15 constitute the first example of a nanometer-sized multi-electron catalyst made of an earth-abundant metal oxide that evolves oxygen from water efficiently. For carbon dioxide reduction, a binuclear unit consisting of a $\mathrm{Zr}$ acceptor and a Cu' donor ( $\mathrm{ZrOCu}$ ') acts as light absorber as well as redox site, splitting $\mathrm{CO}_{2}$ to $\mathrm{CO}$ and $\mathrm{H}_{2} \mathrm{O}$ upon excitation of the charge-transfer transition. Structural and mechanistic insights of the photocatalytic units based on static and time-resolved optical, FT-infrared, FT-Raman, EPR, X-ray absorption spectroscopy and transmission electron microscopy are critical for improving designs. The photocatalytic units presented here form the basis for developing robust and efficient artificial photosynthetic systems for the conversion of carbon dioxide and water to a liquid fuel.
\end{abstract}

Keywords: Artificial photosynthesis · Carbon dioxide reduction · Metal-to-metal charge-transfer . Nanoporous silica $\cdot$ Water oxidation

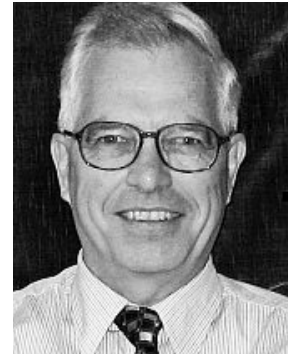

Heinz Frei, a native of Luzern, is a Senior Scientist at Lawrence Berkeley National Laboratory in Berkeley, California, and Deputy Director of the Helios Solar Energy Research Center at LBNL. He studied chemistry at ETH Zürich and received his doctorate degree at ETH in the Laboratory of Physical Chemistry in 1977 (Prof. H. H. Gunthard). After a postdoctoral stay at the Chemistry Department of the University of California at Berkeley, he started a research group in solar photochemistry at LBNL with focus

\footnotetext{
${ }^{\star}$ Correspondence: Dr. H. Frei Physical Biosciences Division Lawrence Berkeley National Laboratory Berkeley, CA 94720

Tel.: +1510486 4325

Fax: +15104867768

E-mail: HMFrei@Ibl.gov
}

on chemistry with near infrared light, work for which he received the Werner Prize in 1990. Over the past two decades, Frei has established new methods for utilizing visible and near infrared light for the environmentally friendly synthesis of useful chemicals, and for the chemical storage of solar photons. Highlights include chargetransfer mediated selective oxidation of alkanes by $\mathrm{O}_{2}$ in zeolites, the development of nanoporous materials functionalized by inorganic photocatalysts for visible light water oxidation and carbon dioxide activation, and the development of time-resolved Fourier-transform infrared spectroscopy for unraveling elementary reaction steps of heterogeneous catalysis under reaction conditions. His current research effort focuses on the scientific challenges of the direct conversion of carbon dioxide and water to a liquid fuel by artificial photosynthesis.

\section{Introduction}

Conversion of carbon dioxide to a low alcohol or hydrocarbon molecule in an artificial system using water as electron donor and sunlight as energy source is an attractive approach for generating a renewable liquid fuel. A look at the very large scale of fuel production needed to replace the bulk of fossil sources (on the order of terawatts (TW) globally, $1 \mathrm{TW}=10^{12} \mathrm{~J} \mathrm{~s}^{-1}$ ) in order to have an impact on the accumulation of atmospheric carbon dioxide, scalability of the method is essential..[1] In this respect, an approach based on a single integrated artificial system for light absorption, charge separation and catalytic transformations made of earth abundant materials and scalable assembly methods is particularly attractive because it minimizes the need for balance of systems components. The goal of artificial photosynthesis has been pursued for decades, ${ }^{[2]}$ yet no system has yet emerged that is sufficiently efficient, durable, made solely of earth-abundant materials and scalable synthetic processes.

One of the major scientific gaps towards this goal is the robustness of the system. For this reason, components made of inorganic materials are of particular interest. In fact, early demonstration of UV light-induced splitting of water to $\mathrm{H}_{2}$, an important energy carrier, and $\mathrm{O}_{2}$ co-product involved stable semiconductor oxides such as $\mathrm{TiO}_{2}$ or $\mathrm{SrTiO}_{3} \cdot{ }^{[2,3]}$ While very efficient and robust photocatalysts for overall water splitting with UV light such as Lasubstituted tantalate have been reported, ${ }^{[4]}$ semiconductor materials for visible light water splitting suitable for use under sunlight remain a challenge. The best material so far for overall splitting of water (without requiring electrical bias) is $\mathrm{GaN}: \mathrm{ZnO}$ solid solution with a quantum efficiency of several percent with blue photons. ${ }^{[5]}$ Much higher hydrogen generation efficiencies 
are achieved with tandem devices, ${ }^{[6]}$ one of them consisting of a PV cell coupled to a photoelectrochemical cell based on III/V semiconductors, ${ }^{[7]}$ but these designs currently utilize material components or assembly methods that are not scalable for fuel generation on the order of terawatts.

For the conversion of carbon dioxide and water, early work based on excitation of large bandgap stable oxides like $\mathrm{TiO}_{2}$ showed formation of methanol or methane along with formic acid and carbon monoxide upon prolonged photolysis. ${ }^{[8-10]} \mathrm{Re}$ duction of $\mathrm{CO}_{2}$ is initiated by transfer of photogenerated conduction band electrons to surface-adsorbed $\mathrm{CO}_{2}$ or carbonate, while valence band holes drive oxidation of $\mathrm{H}_{2} \mathrm{O}$. Although product yields were low and the materials lack the visible absorption properties needed for use of sunlight, the work showed that activation of $\mathrm{CO}_{2}$ by $\mathrm{H}_{2} \mathrm{O}$ by bandgap excitation is feasible. Over the ensuing decades, efforts by the heterogeneous photocatalysis community focused on exploring smaller bandgap semiconductors for carbon dioxide activation by visible light. Particles or colloids with better donor ligands such as $\mathrm{CdS}$ or $\mathrm{ZnSe}$ afford $\mathrm{CO}_{2}$ reduction under visible light but are chemically unstable, requiring sacrificial reductants to suppress irreversible oxidation of the material. ${ }^{[11-13]}$ The need for sacrificial reagents prevents the use of these materials for artificial photosynthesis.

Strong light absorption above the bandgap, and spontaneous separation of positive and negative charges are unique properties of semiconductor materials. Photosynthetic assemblies made of molecular components, on the other hand, benefit from easy tuning of electronic properties, which allows the precise matching of redox potentials of light absorber, charge separator and catalysts. Carefully adjusted potentials are essential for achieving high thermodynamic efficiency. For example, Nature's photocatalyst for water oxidation, Photosystem II, has its component for charge separation (P680 chlorophyll pair), the bridging tyrosine amino acid residue for charge transport, and the Mn tetramer catalyst for oxygen evolution at potentials that gradually decrease in this order. Yet, they lie within just $400 \mathrm{mV}$ of one another.[14] The modest potential gradient assures directed charge transport at minimal loss of energy, resulting in the conversion of a maximum fraction of photon to chemical energy. A structural mimic of Photosystem II made of $\mathrm{Ru}$ and $\mathrm{Mn}$ coordination complexes with similarly matched potentials has recently been demonstrated. ${ }^{[15]}$

Precise tuning of the redox properties is a clear advantage of organic molecular systems, while inorganic components are more durable. In order to combine the ad- vantages of both types of systems, we are exploring an inorganic molecular approach for developing an artificial photosynthetic system. In this article, recent progress towards an all-inorganic polynuclear system for the visible light-driven reduction of $\mathrm{CO}_{2}$ by $\mathrm{H}_{2} \mathrm{O}$ will be presented. The approach is based on heterobinuclear charge-transfer chromophores that drive multi-electron catalysts for water oxidation or $\mathrm{CO}_{2}$ reduction. These photocatalytic units are covalently anchored in nanoporous silica scaffolds. The high surface area of the support is required to achieve a sufficient density of photocatalytic sites in order for all incident photons to be used productively. The nanostructured features offer opportunities for spatially separating the oxidizing from reducing catalytic sites to minimize back reaction.

\section{All-Inorganic Binuclear Units as Robust Charge Transfer Chromophores}

Heterobinuclear charge-transfer chromophores consisting of oxo-bridged metals with appropriately chosen redox potentials are a form of inorganic molecular unit for activating donor and acceptor centers by visible light. With no ligands other than oxygen, such groups are not only robust but absorb light across the visible spectrum. Our first example, a TiOCu ${ }^{\mathrm{I}}$ unit anchored on the surface of nanoporous silica type MCM-41 is shown in Fig. 1.[16] To assemble the binuclear group on the silica nanopore surface, a mild solution-loading method was developed that exploits selective reactivity of the initially anchored metal with the precursor of the subsequently added metal. Following tripodal anchoring of $\mathrm{TiOH}$ groups on the silica nanopore surface (three TiOSi linkages) by an established method, the Ti center was linked via an oxo bridge to $\mathrm{Cu}^{\mathrm{I}}$ using $\mathrm{Cu}^{\mathrm{I}}\left(\mathrm{NCCH}_{3}\right)_{4}$, a precursor whose acetonitrile ligands are only weakly held (Fig. 2a).[16] The precursor reacts preferentially with $\mathrm{TiOH}$ groups to yield $\mathrm{TiOCu}^{\mathrm{I}}$ linkages rather than the much more abundant silanol groups ( $\mathrm{SiOH}$, density of 2-3 groups $\mathrm{nm}^{-2}$ ) to form isolated $\mathrm{Cu}^{\mathrm{I}}$ centers. The higher reactivity of the $\mathrm{TiOH}$ group is due to the slightly higher acidity of titanol compared to surface silanol. ${ }^{[16,18]}$ The concentration of $\mathrm{TiOCu}$ units in the mesoporous silica is between 1 and 2 percent with respect to $\mathrm{Si}$.

Photo-excitation of the chromophore with visible light results in transfer of an electron from $\mathrm{Cu}^{\mathrm{I}}$ (donor) to $\mathrm{Ti}^{\mathrm{IV}}$ (acceptor), generating transient $\mathrm{Ti}^{\mathrm{III}}$ and $\mathrm{Cu}^{\mathrm{II}}$. The optical spectrum of this metal-to-metal

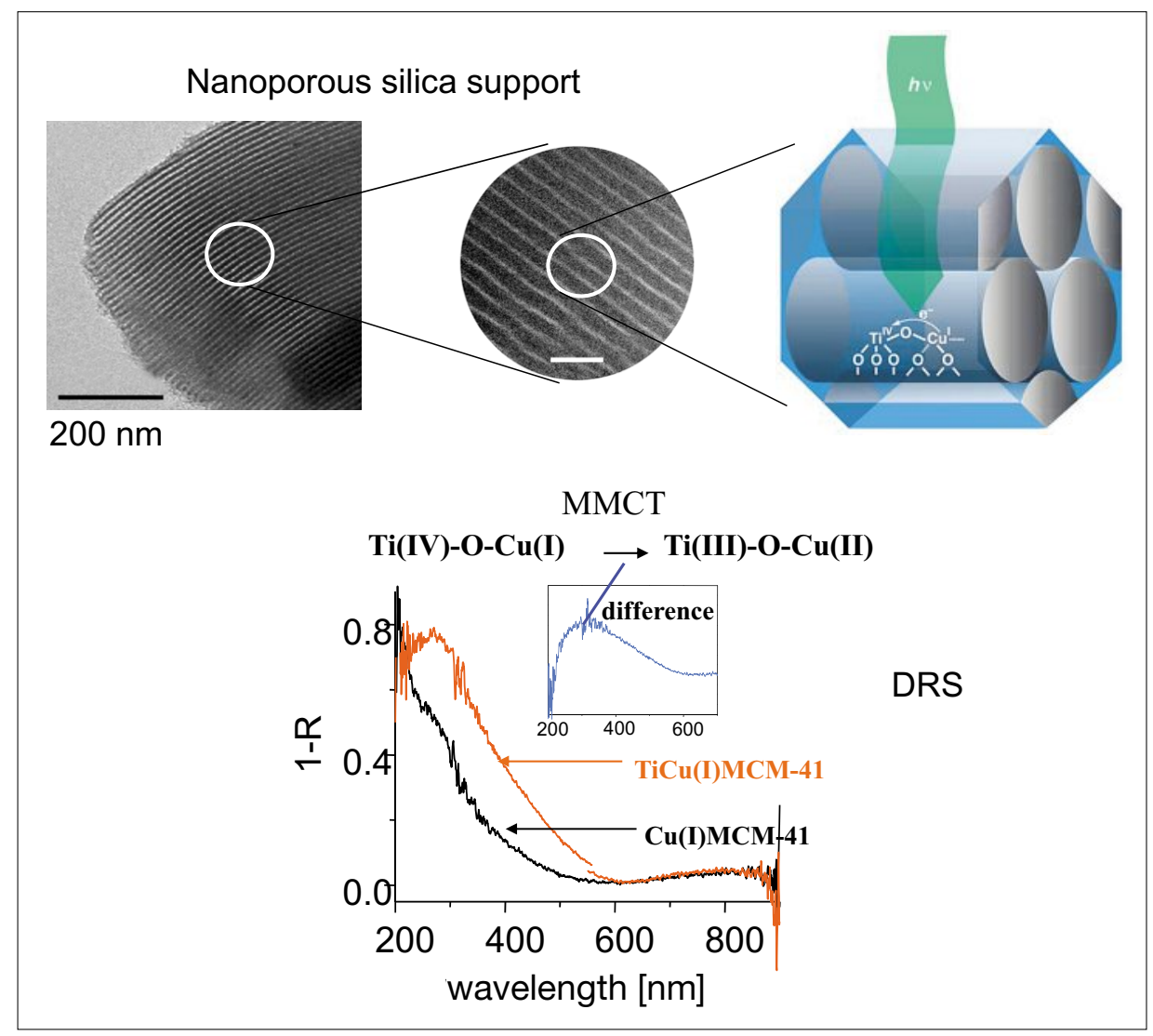

Fig. 1. Binuclear TiOCu' charge-transfer chromophore anchored on the surface of nanoscale silica channels of MCM-41. The high resolution transmission electron microscopic image shows the $30 \AA$ channels of the material, which are separated by $10 \AA$ walls. ${ }^{[17]}$ The visible metal-to-metal charge-transfer absorption is presented in the form of a diffuse reflectance spectrum (DRS). 


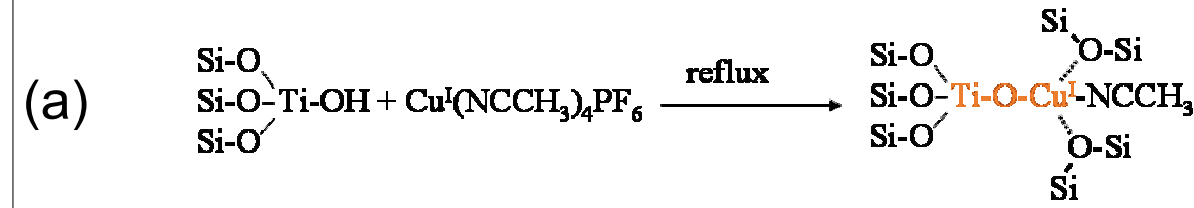

(b)

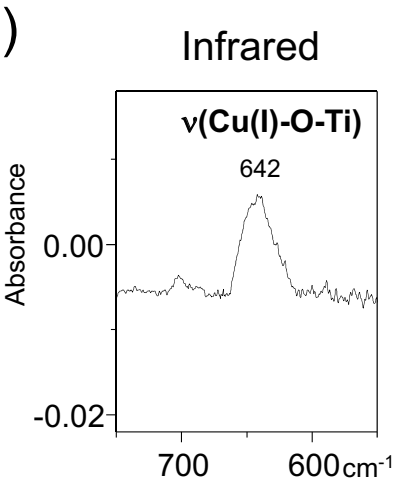

(c)

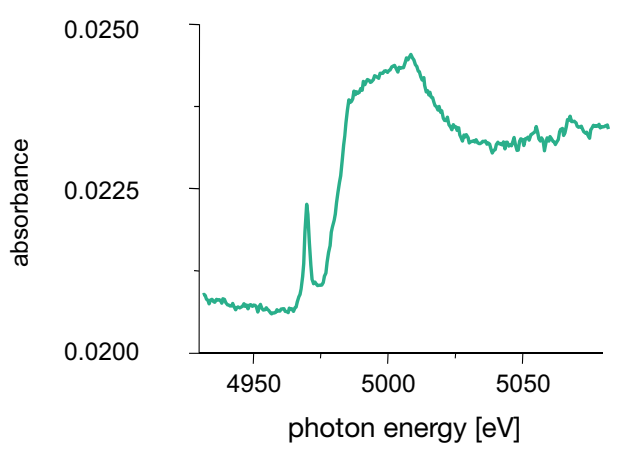

Fig. 2. Spectroscopic characterization of TiOCu' chromophore. (a) Synthesis method. (b) Infrared stretch mode of Cu'OTi group. (c) X-ray absorption near edge structure (XANES) of Ti K-edge of group anchored on silica nanopore surface.

charge-transfer (MMCT) transition, shown in Fig. 1, extends from the UV to $600 \mathrm{~nm}$ in the red. Aside from observing the MMCT band, which requires the two metal centers to be covalently linked, additional spectroscopic signatures of the unit in our early work included an infrared $\mathrm{Cu}^{\mathrm{I}} \mathrm{O}$ mode of the $\mathrm{TiOCu}^{\mathrm{I}}$ unit at $643 \mathrm{~cm}^{-1}$ (Fig. 2b), and the $1 \mathrm{~s}-3 \mathrm{~d}$ absorption band in the pre-edge region of the Ti K-edge of the binuclear unit by X-ray absorption spectroscopy (Fig. 2c). The latter is sensitive to the precise coordination environment of the $\mathrm{Ti}$ center and signals an expected distortion upon formation of a $\mathrm{Ti}-\mathrm{O}-\mathrm{Cu}^{\mathrm{I}}$ linkage. ${ }^{[16]}$ More recently, extended X-ray absorption fine structure (EXAFS) spectroscopy and EPR measurements allowed us to uncover further details of the oxo-bridged structure and the coordination environment of donor or acceptor metal centers, as will be described in more detail below. ${ }^{[18]}$

\section{Photocatalyst for $\mathrm{CO}_{2}$ Splitting}

Since $\mathrm{CO}_{2}$ reduction or $\mathrm{H}_{2} \mathrm{O}$ oxidation are multi-electron transfer processes, driving these reactions with binuclear MMCT units typically requires coupling of the chromophore to a multi-electron transfer catalyst (a concept used by Nature in plant and bacterial photosynthesis $\left.{ }^{[14]}\right)$. Nevertheless, we found that excitation of a $\mathrm{ZrO}$ $\mathrm{Cu}^{\mathrm{I}}$ MMCT chromophore assembled by a method analogous to $\mathrm{TiOCu}^{\mathrm{I}}$ synthesis is capable of activating $\mathrm{CO}_{2}$ even in the absence of a multi-electron catalyst. In this case, the binuclear chromophore itself acts as redox site. When exciting the $\mathrm{Zr}^{\mathrm{IV}} \mathrm{OCu}^{\mathrm{I}}$ $\rightarrow \mathrm{Zr}^{\mathrm{III}} \mathrm{OCu}^{\mathrm{II}} \mathrm{MMCT}$ chromophore of the $\mathrm{ZrOCu}$ site in mesoporous silica MCM-41

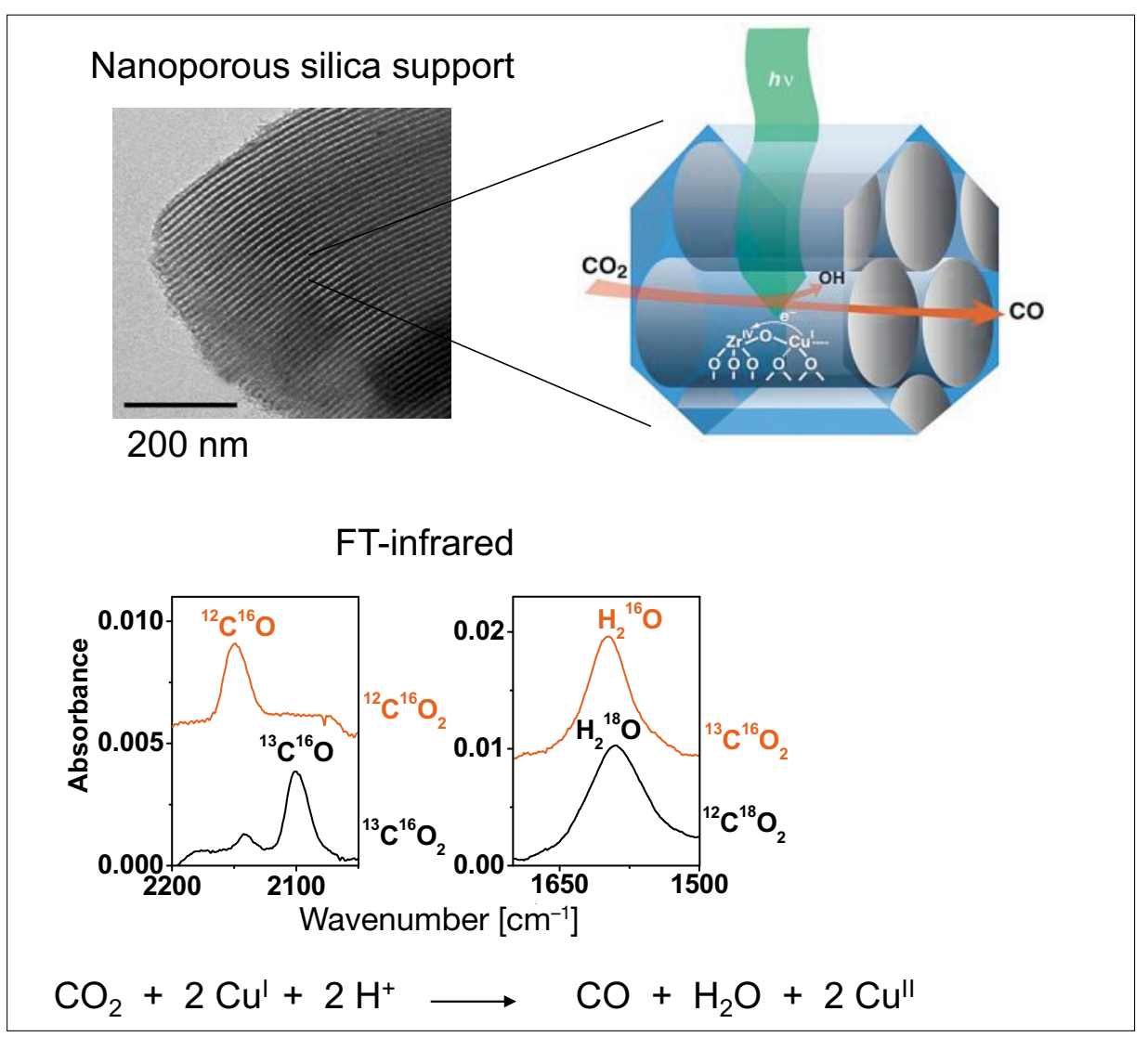

Fig. 3. ZrOCu' metal-to-metal charge-transfer site for photochemical $\mathrm{CO}_{2}$ splitting in silica nanopore. FT-IR spectra of $\mathrm{CO}+\mathrm{H}_{2} \mathrm{O}$ photoproducts of the half reaction using ${ }^{13} \mathrm{C}$ and ${ }^{18} \mathrm{O}$ label carbon dioxide are shown. loaded with 1 atm of gaseous carbon dioxide, splitting of $\mathrm{CO}_{2}$ to $\mathrm{CO}\left(2148 \mathrm{~cm}^{-1}\right)$ and $\mathrm{H}_{2} \mathrm{O}$ as coproduct $\left(1600 \mathrm{~cm}^{-1}\right)$ was observed at room temperature, as shown in Fig. $3^{[19]}$ (in this half-reaction, the protons of $\mathrm{H}_{2} \mathrm{O}$ are supplied by the surface silanol groups. Note that in the complete cycle, the protons are delivered by oxidation of $\mathrm{H}_{2} \mathrm{O}$

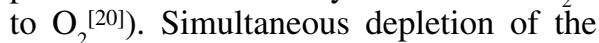
$\mathrm{Cu}^{\mathrm{I}} \mathrm{O}^{2}$ infrared mode of the $\mathrm{ZrOCu}$ group at $643 \mathrm{~cm}^{-1}$ and growth of a $\mathrm{Cu}^{\mathrm{II}} \mathrm{O}$ band at $540 \mathrm{~cm}^{-1}$ confirmed stoichiometric oxidation of the $\mathrm{Cu}$ donor center in this half reaction. Isotopic labeling $\left({ }^{13} \mathrm{C},{ }^{18} \mathrm{O}\right)$ of the carbon dioxide molecule confirmed that $\mathrm{CO}$ and $\mathrm{H}_{2} \mathrm{O}$ are formed by splitting of the carbon dioxide molecule upon capture of an electron from transient $\mathrm{Zr}^{\mathrm{III}}$. Most probably, $\mathrm{CO}_{2}$ molecules in transient contact with the $\mathrm{Z}$ r center and a hydroxyl group of an adjacent surface $\mathrm{SiOH}$ form a transient HOCO (hydroxyl carbonyl) intermediate that splits into $\mathrm{CO}$ and hydroxyl. The latter is reduced at $\mathrm{Cu}^{\mathrm{I}}$ center to water, thus explaining the formation of $\mathrm{H}_{2}{ }^{18} \mathrm{O}$ from $\mathrm{C}^{18} \mathrm{O}_{2}$ (Fig. 3). This is the first observation of two-electron photoreduction of $\mathrm{CO}_{2}$ at an all-inorganic binuclear redox site.

Use of nanoporous silica support for artificial photosynthesis offers a means for achieving high densities of photocatalytic sites in a robust scaffold as well as opportunities for ultimately separating 
reduction and oxidation sites by physical barriers. However, an important question is whether adsorption of reactants or desorption of products from the nanopores proceeds at rates sufficiently fast compared to catalytic turnovers so as not to impose rate limitations. We are employing timeresolved (step-scan) FT-IR absorption spectroscopy for the direct monitoring of transient species inside nanoporous silica on the nanosecond to millisecond time scale. ${ }^{21]}$ Release of CO inside the channels of MCM-41 by a nanosecond laser pulse from a photolabile precursor loaded into the material (a cyclopropene) allowed us to directly observe diffusion and escape of the product from the support (Fig. 4). ${ }^{[22]}$ The majority of the molecules escape within 340 microseconds (diffusion constant $1.5 \times 10^{-9} \mathrm{~m}^{2} \mathrm{~s}^{-1}$, room temperature), which is fast on the timescale of catalytic turnover (tens of milliseconds to seconds). The spectral profile of Fig. 4 reveals the sites which the hopping $\mathrm{CO}$ molecules get in contact with during diffusion through the channels: Surface $\mathrm{SiOH}$ groups $\mathrm{C}$ endon $\left(2167 \mathrm{~cm}^{-1}\right), \mathrm{O}$ end-on $\left(2105 \mathrm{~cm}^{-1}\right)$, and siloxane moieties ( $\mathrm{SiOSi}$ ) of the pore wall (absorption around $2140 \mathrm{~cm}^{-1}$ ).

Two-electron photoreduction of $\mathrm{CO}_{2}$ is the thermodynamically most demanding step of the six-electron transfer chemistry needed for the conversion to methanol. Reduction to $\mathrm{CH}_{3} \mathrm{OH}$ requires coupling of a binuclear charge-transfer chromophore to a multi-electron catalyst capable of accomplishing this transformation. Such attempts are in progress in our laboratory.

\section{Binuclear Metal-to-Metal Charge-Transfer Chromophores Made of Abundant First Row Transition Metals}

In artificial photosynthesis, two types of visible charge-transfer chromophores are of interest: Units that generate a transient acceptor upon photoexcitation with sufficiently negative potential for reducing $\mathrm{CO}_{2}$ molecules, for which $\mathrm{ZrOCu}^{\mathrm{I}}$ is a first example. Binuclear charge-transfer chromophores suitable for driving a multi-electron catalyst for water oxidation need to have a donor center which, after photo-induced charge transfer, achieves a redox potential in the range $1.1-1.8 \mathrm{~V}\left(\varepsilon^{\circ}=0.82 \mathrm{~V}\right.$ is required for oxygen evolution from water at neutral $\mathrm{pH}$ ). Donor centers with much more positive potential would substantially diminish the photon to chemical energy conversion efficiency. The range of oxidation states and redox potentials accessible for transition metals makes them particularly well suited for this purpose. Furthermore, among transition metals, those of the first

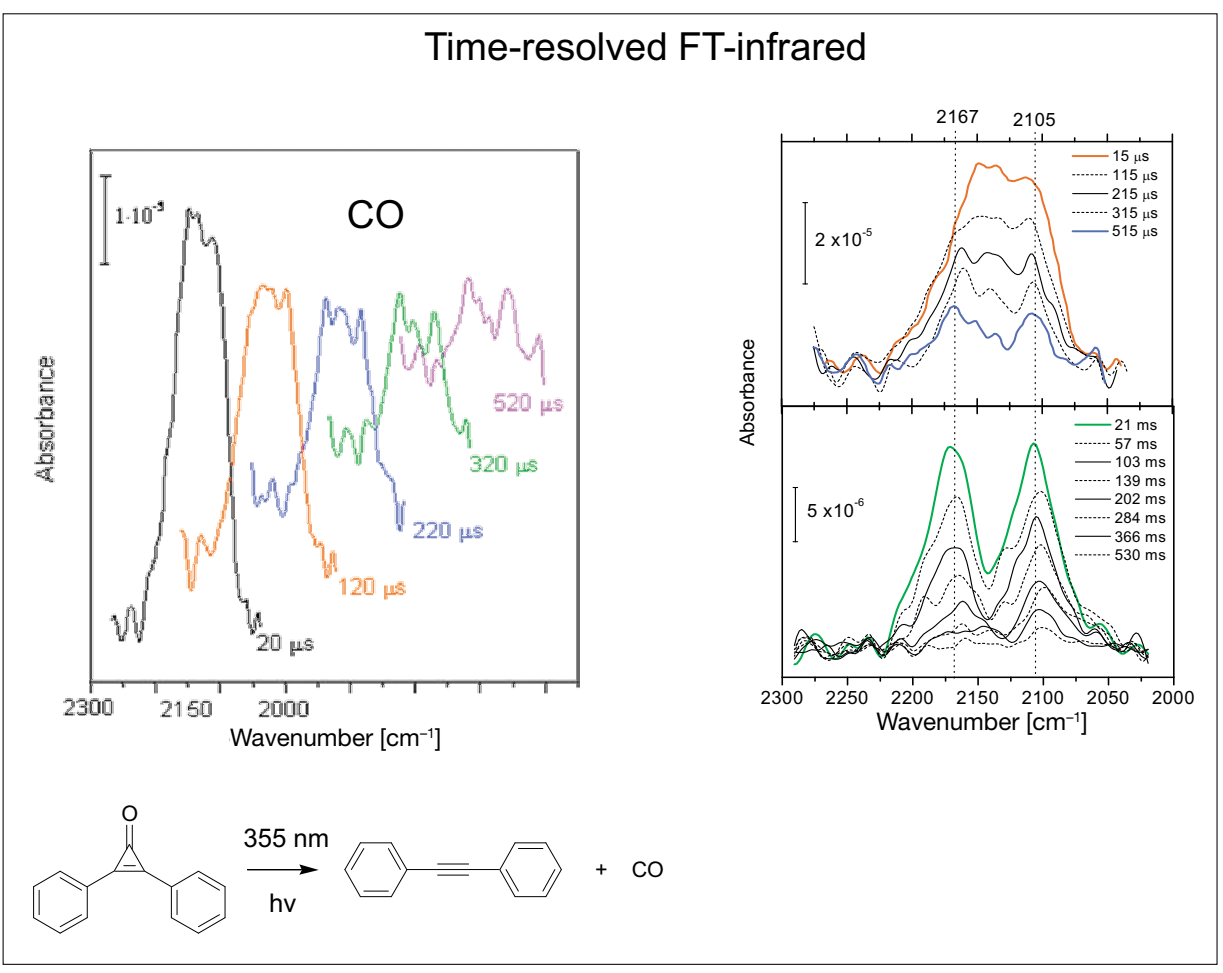

Fig. 4. Time-resolved step-scan FT-IR spectroscopy of CO dynamics in nanoscale channels of MCM-41 silica at room temperature. CO was released from a cyclopropene precursor inside the channels by a 5 nanosecond photolysis pulse. The majority of the molecules escape from the channels (about 1 micrometer long) within 500 microseconds (the residual sites lasting for a few hundred milliseconds are CO trapped by the organic co-product $\left.{ }^{[22]}\right)$.

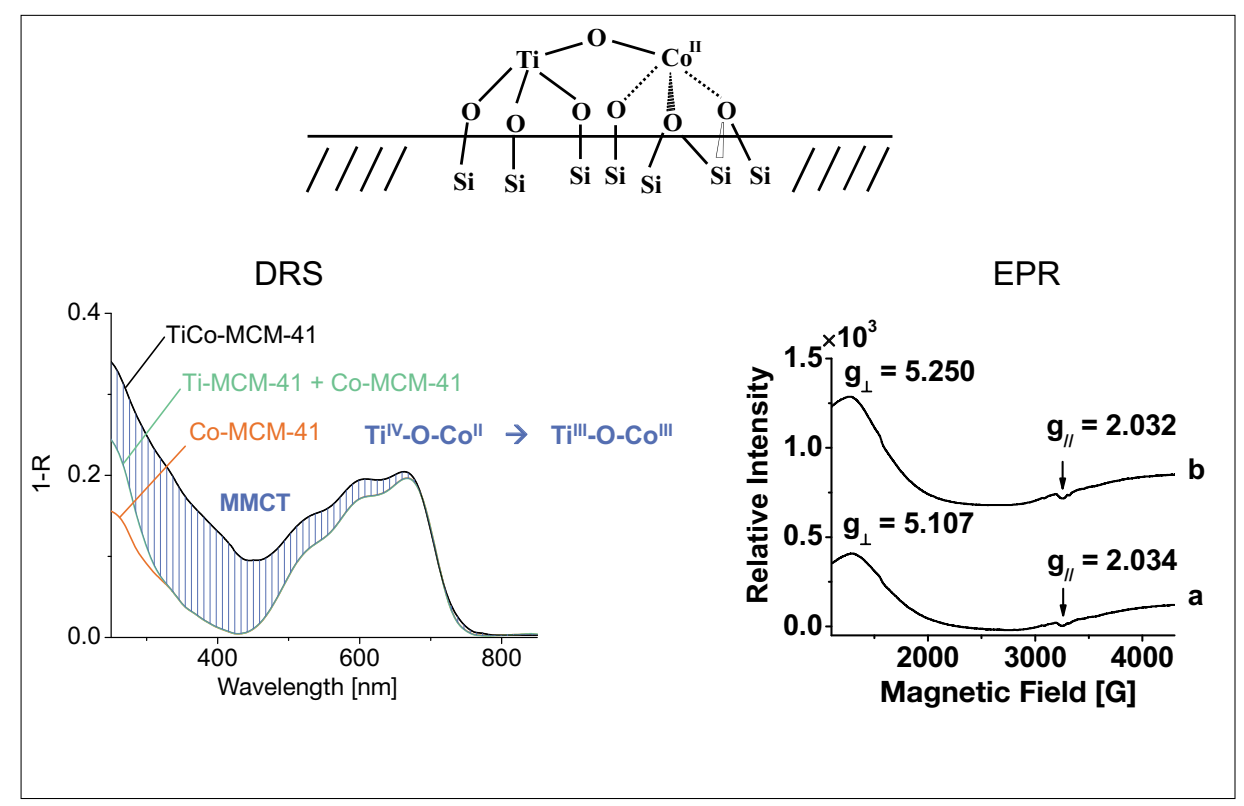

Fig. 5. Visible light absorbing TiOCo"l charge-transfer unit anchored in MCM-41 silica pores. The shaded area of the optical spectrum shows the metal-to-metal charge-transfer absorption. $\mathrm{g}$-values derived from the EPR spectrum indicate that $\mathrm{Co}^{\prime \prime}$ is in high spin tetrahedral configuration.

row are preferred because of their earth abundance.

By exploiting the general utility of the synthetic method based on precursors with weakly held ligands, ${ }^{[16,19]}$ our and the Tokyo group have assembled oxo-bridged binuclear charge transfer units featuring $\mathrm{Co}^{\mathrm{II}}$, $\mathrm{Mn}^{\mathrm{II}}, \mathrm{Cr}^{\mathrm{III}}$, or $\mathrm{Ce}^{\mathrm{III}}$ as donor and $\mathrm{Ti}^{\mathrm{IV}}$ as acceptor. ${ }^{[18,23,24]}$ The $\mathrm{TiOCO}^{\mathrm{II}}$ unit has a broad MMCT absorption extending from the UV region to $700 \mathrm{~nm}$, as shown in the diffuse reflectance optical spectrum (DRS) of Fig. 5 (difference of spectra of $\mathrm{TiCo}^{\mathrm{II}}$ and $\mathrm{Co}^{\mathrm{II}}$ MCM-41, blue-shaded area). The characteristic spin-orbit peaks of the visible spectrum and the EPR signal (Fig. 5) indicate that the $\mathrm{Co}^{\mathrm{II}}$ is tetrahedrally coordinated and in high-spin configuration. Close to all $(98 \%)$ of the Co centers are linked via an oxo bridge to a Ti center at a loading of $1 \%$ 
$(\mathrm{Co} / \mathrm{Si}=1 / 100) .{ }^{[18]}$ With a redox potential of $1.8 \mathrm{~V}$, the transient $\mathrm{Co}^{\mathrm{III}}$ donor generated upon MMCT excitation $\mathrm{Ti}^{\mathrm{IV}} \mathrm{OCO}^{\mathrm{II}} \rightarrow \mathrm{Ti}^{\mathrm{III}} \mathrm{O}$ $\mathrm{Co}^{\mathrm{III}}$ has adequate oxidizing power to drive a water oxidation catalyst. (The $\mathrm{Co}^{\mathrm{III}}$ redox potential of $1.8 \mathrm{~V}$ refers to the hexaaqua complex, not to the Co center anchored on the silica surface. The redox potential for the surface-anchored center might be less positive because of the slightly more electron-donating coordination environment. Since electrochemical measurements are not feasible, theoretical methods need to be engaged to address this question). Or, $\mathrm{Ce}^{\mathrm{III}}$ can be linked to a Ti center to form a TiOCe unit with a $\mathrm{Ti}^{\mathrm{IV}} \mathrm{OCe}^{\mathrm{III}} \rightarrow \mathrm{Ti}^{\mathrm{III}} \mathrm{O}-$ $\mathrm{Ce}^{\mathrm{IV}}$ charge-transfer absorption covering the blue and green spectral region (DRS of Fig. 6, shaded area between $\mathrm{TiCe}^{\mathrm{III}}$ and Ce ${ }^{\text {III }}$-MCM-41 spectra). ${ }^{[18]}$ Here, X-ray absorption spectroscopy of the Ce L-edge furnished the most accurate means of determining the oxidation state of the $\mathrm{Ce}$ linked to the Ti center. As shown in Fig. 6 , the Ce $2 p-4 f / 5 d$ splitting is distinct for the $\mathrm{Ce}^{\mathrm{III}}$ and $\mathrm{Ce}^{\mathrm{IV}}$ oxidation states. ${ }^{[18,24]}$ The redox potential of $\mathrm{Ce}^{\mathrm{IV}}$ is $1.7 \mathrm{~V}$, again suitable for driving a water oxidation catalyst. While extensive work has been done on heterobinuclear organometallic MMCT systems featuring electron-rich cyano or aromatic hydrocarbon bridges, ${ }^{[25]}$ no precedent exists for all-inorganic binuclear systems. However, there are many mixed solid metal oxides, some occurring in stones that exhibit strong colors caused by MMCT absorptions of oxo-bridged metal centers. [26]

For such a binuclear charge-transfer unit to be useful for driving a catalyst, the excited state has to be sufficiently long lived to allow for electron transport to (or from) the multi-electron catalyst it is coupled to. We have conducted a transient optical absorption study of a $\mathrm{Ti}^{\mathrm{IV}} \mathrm{OMn}^{\mathrm{II}}$ unit anchored on silica nanopore surfaces to measure the back electron transfer rate following MMCT excitation. ${ }^{[27]}$ This unit was selected for time-resolved studies because the charge-transfer absorption strongly dominates the spectral region in the visible $\left(\mathrm{Mn}^{\mathrm{II}}\right.$ ligand field absorptions in the visible are very weak). Because TiMn-MCM-41 particles are of micrometer size, powders of the material strongly scatter visible light. Hence, transient absorption experiments require the use of an index-matching liquid such as mineral oil, silicone oil or chloroform that closely matches the refractive index of silica. As shown in Fig. 7, excitation of the $\mathrm{Ti}^{\mathrm{IV}} \mathrm{OMn}^{\mathrm{II}} \rightarrow \mathrm{Ti}^{\mathrm{III}} \mathrm{OMn}^{\mathrm{III}}$ absorption at $420 \mathrm{~nm}$ results in transient bleach that recovers with a first order rate constant of 1.6 microseconds. The transient signal is dominated at all probe wavelengths by the depletion of the MMCT ground state; at $450 \mathrm{~nm}$ and shorter wavelengths, excited

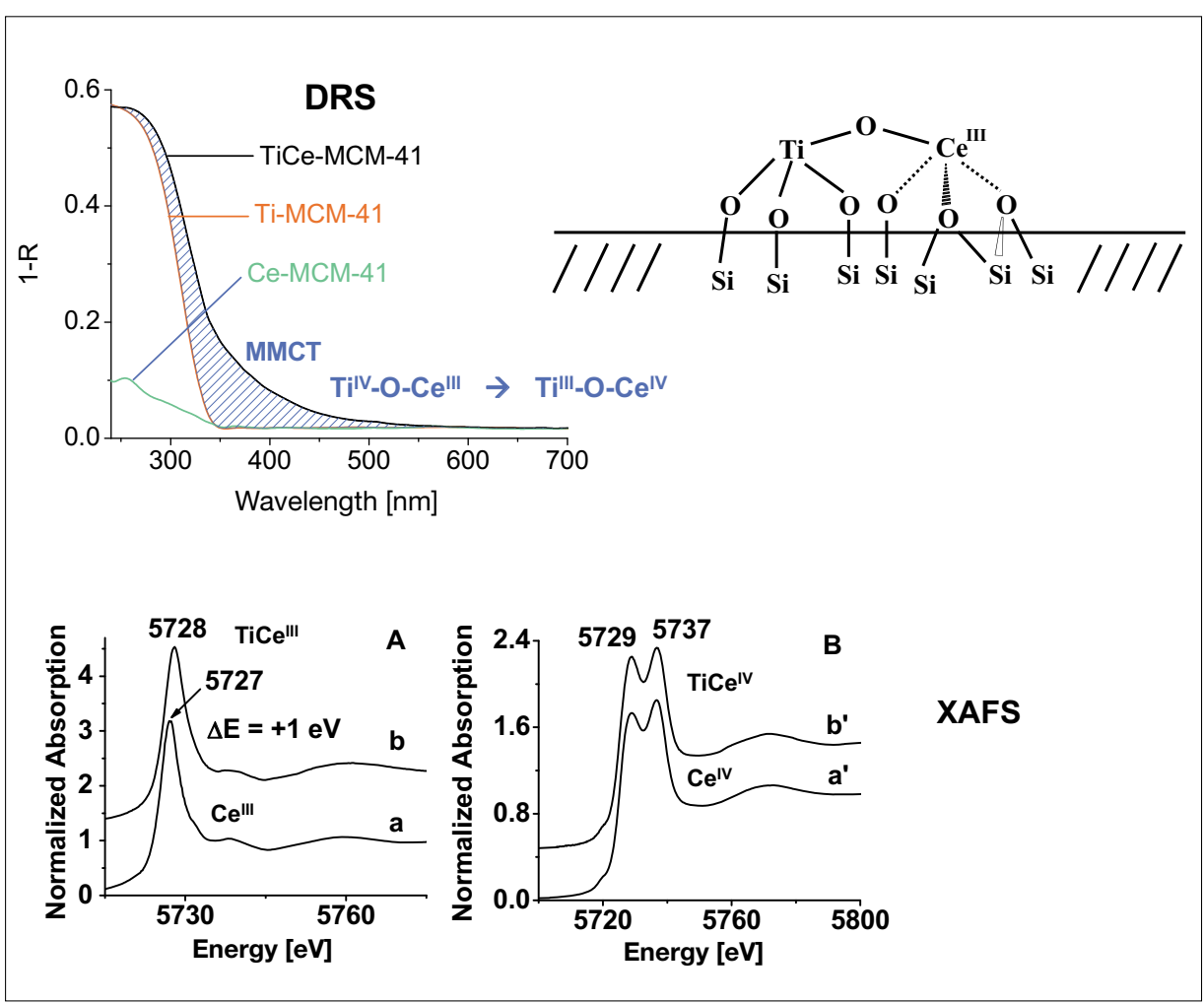

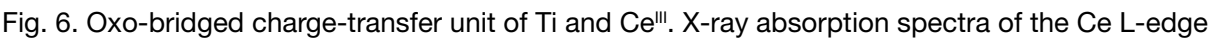
afford accurate assessment of the oxidation state of the binuclear group. The shaded area of the DRS shows the MMCT absorption.

state absorption of transient Mn(III) also contributes to the spectrum. ${ }^{[27]}$

The significance of the time-resolved measurement is that the decay kinetics

reveals the rate of back electron transfer from $\mathrm{Ti}^{\mathrm{III}}$ to $\mathrm{Mn}^{\mathrm{III}}$, regenerating the $\mathrm{Ti}^{\mathrm{IV}} \mathrm{OMn}^{\mathrm{II}}$ ground state. For the quantum efficiency of a photocatalyst to be in an

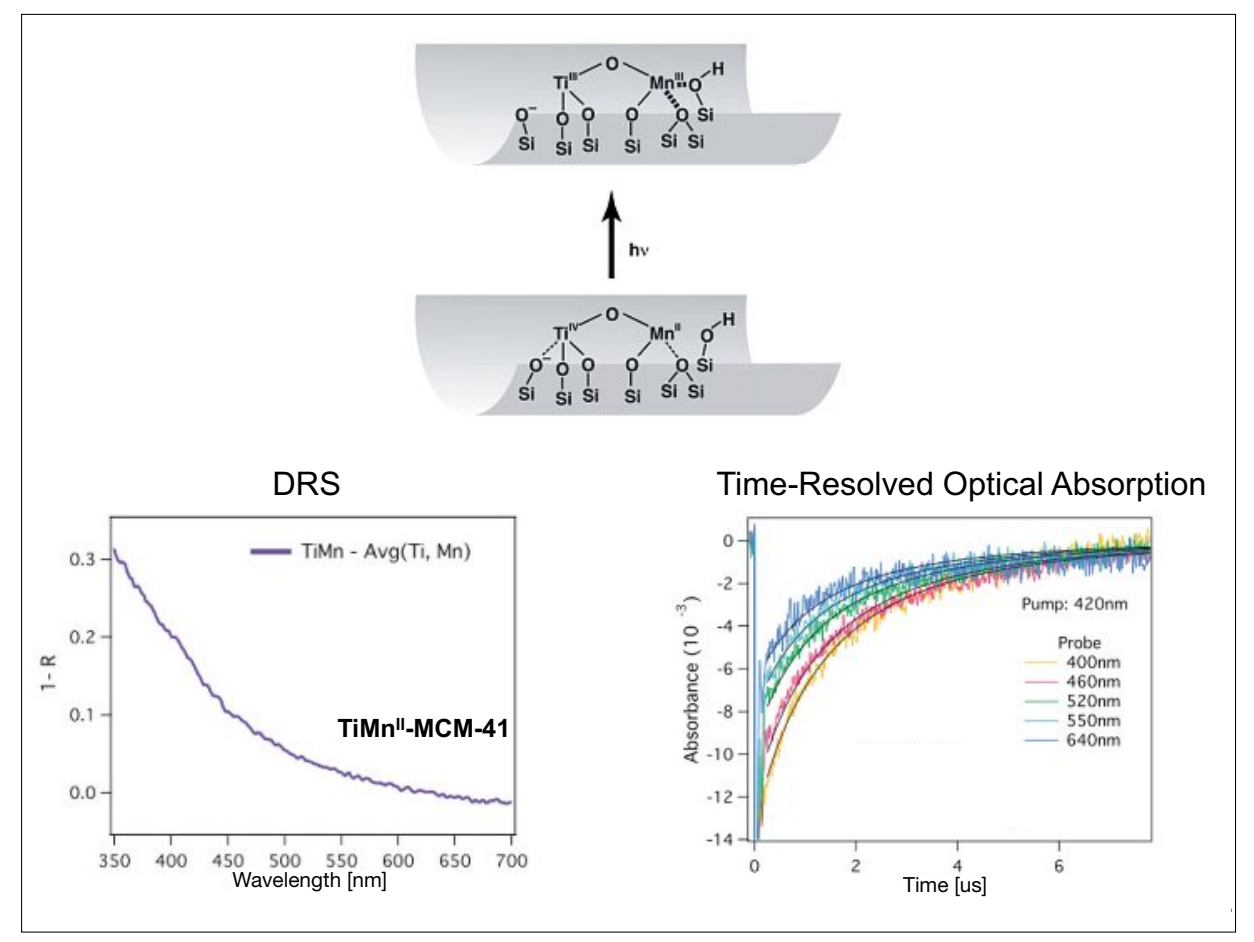

Fig. 7. Transient optical absorption spectroscopy of the TivOMn" $\rightarrow \mathrm{Ti}^{\mathrm{i}} \mathrm{IOMn} \mathrm{OM}^{\text {"II }}$ unit in mesoporous silica SBA-15 (one-dimensional channels of $80 \AA \AA$ diameter ${ }^{[28]}$ ). The charge-transfer absorption (static DRS) and time-resolved optical spectra of the recovery of the ground state bleach at various probe wavelengths are shown. Solid curves represent fits to a dispersive first order kinetic model with a mean time constant 1.6 microseconds (the dispersive kinetics originates from structural heterogeneity of the amorphous silica pore surface environment of the TiOMn site). 
acceptable range, this rate needs to be slow compared to forward electron transfer from the water oxidation catalyst to the oxidized donor $\left(\mathrm{Mn}^{\mathrm{III}}\right.$ in this case). A rate in the microsecond regime at room temperature looks favorable. While there are no precedents for lifetimes of MMCT states of such heterobinuclear units free of organic ligands, we propose that the unusually long lifetime is caused by substantial structural rearrangement of the silica coordination environment upon photo-induced charge transfer, resulting in a considerable reorganization barrier for back electron transfer. ${ }^{[27]}$ While there is no precedent for such all-inorganic heterobinuclear systems, analogous effects of protein environments on influencing back electron transfer in biological charge-transfer systems have been reported.[29]

Another synthetic method for the assembly of heterobinuclear chromophores is based on selective redox reactivity between an anchored metal center and a precursor of the second metal. The method was used to assemble a $\mathrm{TiOCr}^{\mathrm{III}}$ unit on silica nanopores featuring a $\mathrm{Ti}^{\mathrm{IV}} \mathrm{OCr}^{\mathrm{III}} \rightarrow$ $\mathrm{Ti}^{\mathrm{III}} \mathrm{OCr}^{\mathrm{IV}}$ charge-transfer chromophore (in this case, $2 \% \mathrm{Al}$ was incorporated into the MCM-41 framework in order to minimize leaching of $\mathrm{Cr}$ when the materials was exposed to aqueous solution). Starting with isolated tetrahedral $\mathrm{Cr}^{\mathrm{VI}}$ centers anchored on the pore surface, a $\mathrm{Ti}^{\mathrm{III}}$ precursor $\left(\mathrm{Ti}(\mathrm{THF})_{3} \mathrm{Cl}_{3}\right.$, THF = tetrahydrofuran) was loaded into the silica pores resulting in spontaneous redox coupling to yield $\mathrm{Ti}^{\mathrm{IV}} \mathrm{OCr}^{\mathrm{V}}$ units as indicated by the appearance of the $\mathrm{Cr}^{\mathrm{V}}$ signal in the EPR spectrum (Fig. 8). The process was accompanied by the simultaneous disappearance of the $\mathrm{O}=\mathrm{Cr}=\mathrm{O}$ stretch of $\mathrm{Cr}^{\mathrm{VI}}$ in the FT-Raman spectrum and of the $\mathrm{Cr}^{\mathrm{VI}} \mathrm{O}$ LMCT band in the optical spectrum. ${ }^{[18]}$ The reaction of $\mathrm{Ti}^{\mathrm{III}}$ precursor with $\mathrm{Cr}^{\mathrm{VI}}$ centers is completely selective because $\mathrm{Si}$ surface centers do not exhibit any redox reactivity. Treatment with hydroxylamine reduced all $\mathrm{Cr}^{\mathrm{V}}$ centers to $\mathrm{Cr}^{\mathrm{III}}$, leading to the formation of the $\mathrm{Ti}^{\mathrm{IV}} \mathrm{OCr}^{\mathrm{III}} \rightarrow \mathrm{Ti}^{\mathrm{III}} \mathrm{OC}$ $\mathrm{r}^{\mathrm{IV}} \mathrm{MMCT}$ band extending from the UV to $600 \mathrm{~nm}$ (red-shaded area between DRS of $\mathrm{TiCr}^{\mathrm{III}}$ and $\mathrm{Cr}{ }^{\mathrm{III}}-\mathrm{MCM}-41$, Fig. 8). Curve fitting analysis of extended X-ray absorption fine structure (EXAFS) data of the $\mathrm{Cr} \mathrm{K}$ edge indicates a $\mathrm{Cr}-\mathrm{Ti}$ distance of 3.14 A (Fig. 8).

These examples show that the synthetic methods are quite general and flexible, which is the key for making visible light charge transfer chromophores with selectable redox potential for acceptor and donor centers. This property is essential for matching the redox energetics of chromophore and catalyst, a prerequisite for thermodynamic efficiency.
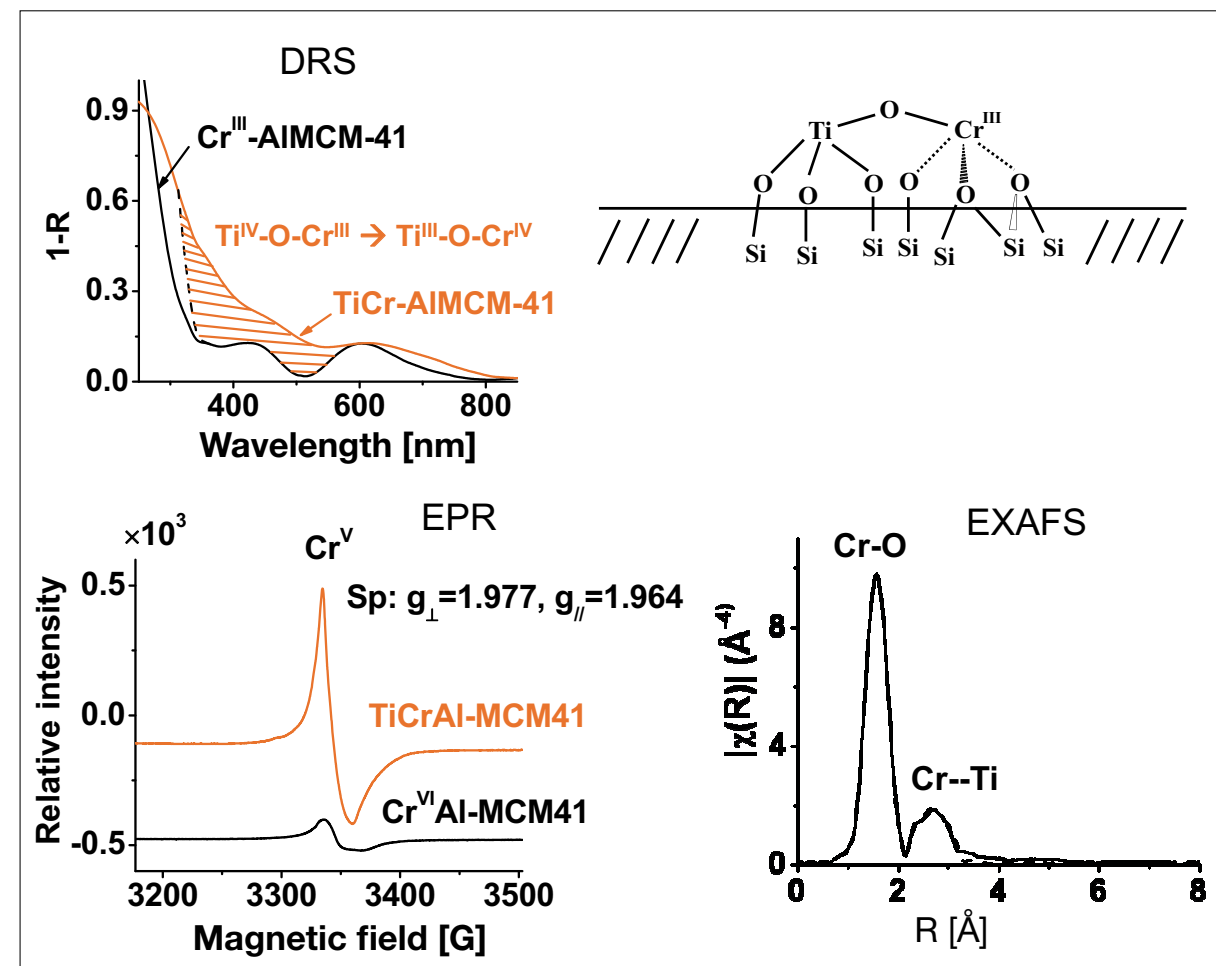

Fig. 8. TiOCr chromophore assembled by a selective redox coupling method. The red-shaded area in the optical DRS shows the MMCT absorption. EPR traces before (black) and after (red) indicate the reduction of $\mathrm{Cr}^{\mathrm{Vl}}$ surface site by $\mathrm{Ti}^{\mathrm{II}}$ precursor upon formation of $\mathrm{Ti}^{\mathrm{i}} \mathrm{OCr}^{\mathrm{V}}$ units. The second shell $\mathrm{Cr}$-Ti peak of the FT-EXAFS curve gives direct evidence for the oxo-bridged structure of the chromophore.

\section{Photocatalytic Units for Water Oxidation}

\subsection{IrO Nanocluster Catalyst Driven by TiOCr'll Chromophore}

Illumination of the $\mathrm{TiOCr}^{\mathrm{III}}$ chromophore with visible light results in the generation of a transient $\mathrm{Cr}^{\mathrm{IV}}$ center. While the true redox potential of $\mathrm{Cr}^{\mathrm{IV}}$ anchored on a silica surface is not known, the potential of $\mathrm{Cr}^{\mathrm{IV}}$ in acidic solution is just under $2 \mathrm{~V}$ and, therefore, the surface-anchored center is expected to have sufficient driving force for oxidizing water to $\mathrm{O}_{2}$. In an attempt to assemble a unit consisting of an Ir oxide nanocluster catalyst coupled to the $\mathrm{Cr}$ donor center of the TiOCr chromophore, a solution of $\operatorname{Ir}^{\mathrm{III}}(\mathrm{acac})_{3}$ (acac = acetyl acetonate) was loaded into mesoporous silica containing $\mathrm{TiOCr}^{\mathrm{V}}$ sites. ${ }^{[30]}$ Redox reaction of the Ir precursor with the $\mathrm{Cr}^{\mathrm{V}}$ led to coupling of the two centers; the bridge mode of a Cr-O-Ir linkage at $808 \mathrm{~cm}^{-1}$ was directly observed by FT-Raman spectroscopy when starting with single $\mathrm{Cr}$ centers. ${ }^{[31]}$ Calcination of the sample under mild conditions resulted in the formation Ir oxide nanoclusters of about $2 \mathrm{~nm}$ diameter observed by high-resolution transmission electron microscopy (HR-TEM, Z-contrast mode). The image, shown in Fig. 9, demonstrates that the silica channels remain unperturbed by the Ir oxide clusters, and the elemental composition of the cluster was confirmed by energy dispersive X-ray spot analysis. Ir oxide was selected as water oxidation catalyst because of its high efficiency and robustness, established previously by use as anode coating in electrochemical cells and by chemical oxidation experiments with $\mathrm{IrO}_{2}$ colloids. ${ }^{[32-37]}$ More recently, Ir oxide nanoparticles were used as catalyst in a water splitting dye-sensitized solar cell.[38] EPR spectra revealed that the $\mathrm{Cr}$ centers of the $\mathrm{TiOCr}-\mathrm{IrO}_{2}$ units are essentially all in oxidation state III.

Suspension of the silica particles containing the $\mathrm{TiOCr}^{\mathrm{III}}$-- $\mathrm{IrO}_{2}$ photocatalysts in buffered aqueous solution (pH 5.7) and excitation of the TiOCr ${ }^{\text {III }}$ MMCT absorption with blue light $(460 \mathrm{~nm}, 100 \mathrm{~mW})$ resulted in evolution of $\mathrm{O}_{2}$. In order for the chromophore to continuously drive the Ir oxide catalyst, persulfate, an established acceptor for water oxidation half reactions ${ }^{[37]}$ was used; the $\mathrm{S}_{2} \mathrm{O}_{8}{ }^{-2}$ species reoxidizes transient $\mathrm{Ti}^{\mathrm{III}}$ thereby restoring the ground state of the MMCT unit. The oxygen buildup in solution was monitored electrochemically by an $\mathrm{O}_{2}$-selective Clark electrode. Based on the oxygen concentration versus time plot shown in Fig. 9, a lower limit of $13 \%$ for the quantum efficiency was derived. ${ }^{[30]}$ This good quantum efficiency points to quite efficient coupling of the Ir oxide nanocluster 
with the $\mathrm{Cr}$ donor of the binuclear $\mathrm{TiOCr}$ chromophore.

Surprisingly at first, the $\mathrm{O}_{2}$ buildup levels off after about an hour (Fig. 9). In situ monitoring of the solution by FT-Raman spectroscopy revealed the formation of superoxide intermediate $\left(\mathrm{O}_{2}^{-}, 994 \mathrm{~cm}^{-1}\right)$, which carried the ${ }^{18} \mathrm{O}$ isotopic label when using $\mathrm{H}_{2}{ }^{18} \mathrm{O}$, as shown in Fig. 10(a). Hence, the water oxidation product is trapped in the form of superoxide. Concurrent EPR measurements revealed that $\mathrm{O}_{2}^{-}$is engaged in a complex with tetrahedral $\mathrm{Ti}^{\mathrm{IV}}$ centers, which suggests a mechanism by which superoxide is formed: Upon excitation of the $\mathrm{Ti}^{\mathrm{IV}} \mathrm{OCr}^{\mathrm{III}} \rightarrow \mathrm{Ti}^{\mathrm{III}} \mathrm{OCr}^{\mathrm{IV}}$ charge-transfer state, the $\mathrm{Cr}^{\mathrm{IV}}$ donor pulls an electron from Ir oxide nanocluster while being reduced back to $\mathrm{Cr}^{\mathrm{III}}$. At the same time, transient $\mathrm{Ti}^{\mathrm{III}}$ is reoxidized by persulfate to $\mathrm{Ti}^{\mathrm{IV}}$. This restores the visible MMCT chromophore and allows continued excitation and extraction of electrons from the catalyst. As $\mathrm{O}_{2}$ product accumulates in solution, it begins to compete with persulfate for reaction with transient $\mathrm{Ti}^{\mathrm{III}}$ and is thereby trapped as $\mathrm{Ti}^{\mathrm{IV}}-\mathrm{O}_{2}^{-}$. In fact, $\mathrm{Ti}^{\mathrm{III}}$ accumulates if no persulfate is added to the reaction mixture, as shown by the EPR signal of Fig. 10(c). This observation confirms that electron transfer from the $\mathrm{IrO}_{2}$ catalyst to the transient $\mathrm{Cr}^{\mathrm{IV}}$ center is competitive with back electron transfer from $\mathrm{Ti}^{\mathrm{III}}$ even in the absence of an electron acceptor. ${ }^{[30]}$ We conclude that efficient coupling of the multi-electron catalyst with the chromophore is responsible for the good quantum efficiency of this all-inorganic photocatalyst for water oxidation.

\subsection{Spectroscopic Monitoring of Visible Light-Induced Electron Transfer between Chromophore and Catalyst}

Efficient charge-transport coupling between chromophore and multi-electron transfer catalyst is essential to achieve high quantum yields for photosynthetic transformations. Detailed evaluation of visible light-induced charge transport processes between the components is therefore critical but requires spectroscopic monitoring of the electronic states of catalyst and chromophore. While metal oxide nanoclusters are favored catalysts because of their stability, monitoring of detailed electronic state changes is very challenging. The state of the metal oxide core of a polynuclear organometallic complex, on the other hand, can be followed accurately by molecular spectroscopy. Taking advantage of di$\mu$-oxo Mn dimer complexes developed by the biomimetic photosynthesis community that serve as structural models of Nature's Photosystem II oxygen evolving complex, ${ }^{[39,40]}$ we have undertaken a spec-

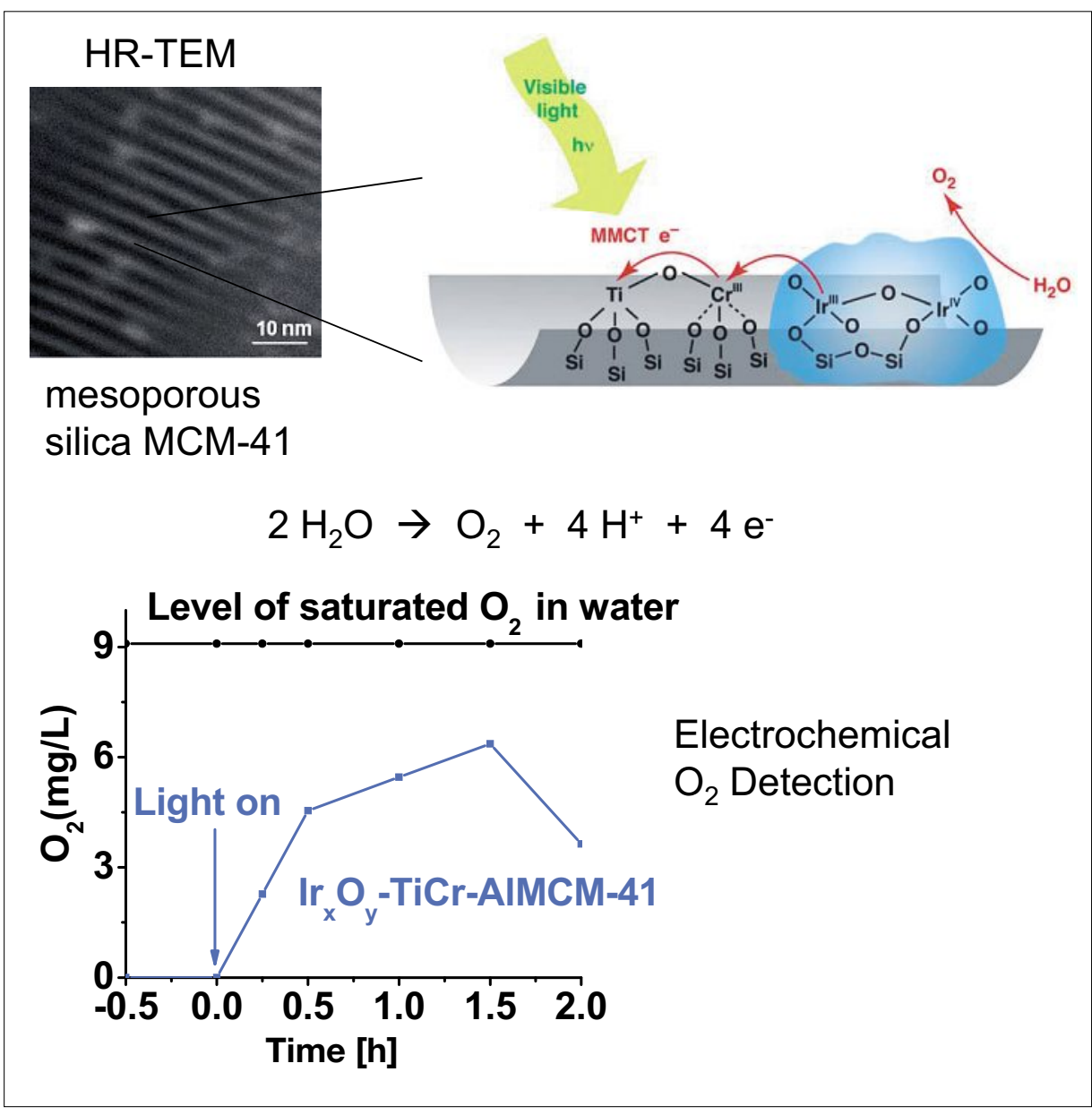

Fig. 9. Polynuclear TiOCr'll-IrO ${ }_{2}$ photocatalyst for water oxidation in nanoporous silica. HR-TEM of Ir oxide nanoclusters $(2 \mathrm{~nm})$ inside silica channels. The plot shows visible light-driven $\mathrm{O}_{2}$ evolution in aqueous solution monitored by a Clark electrode.

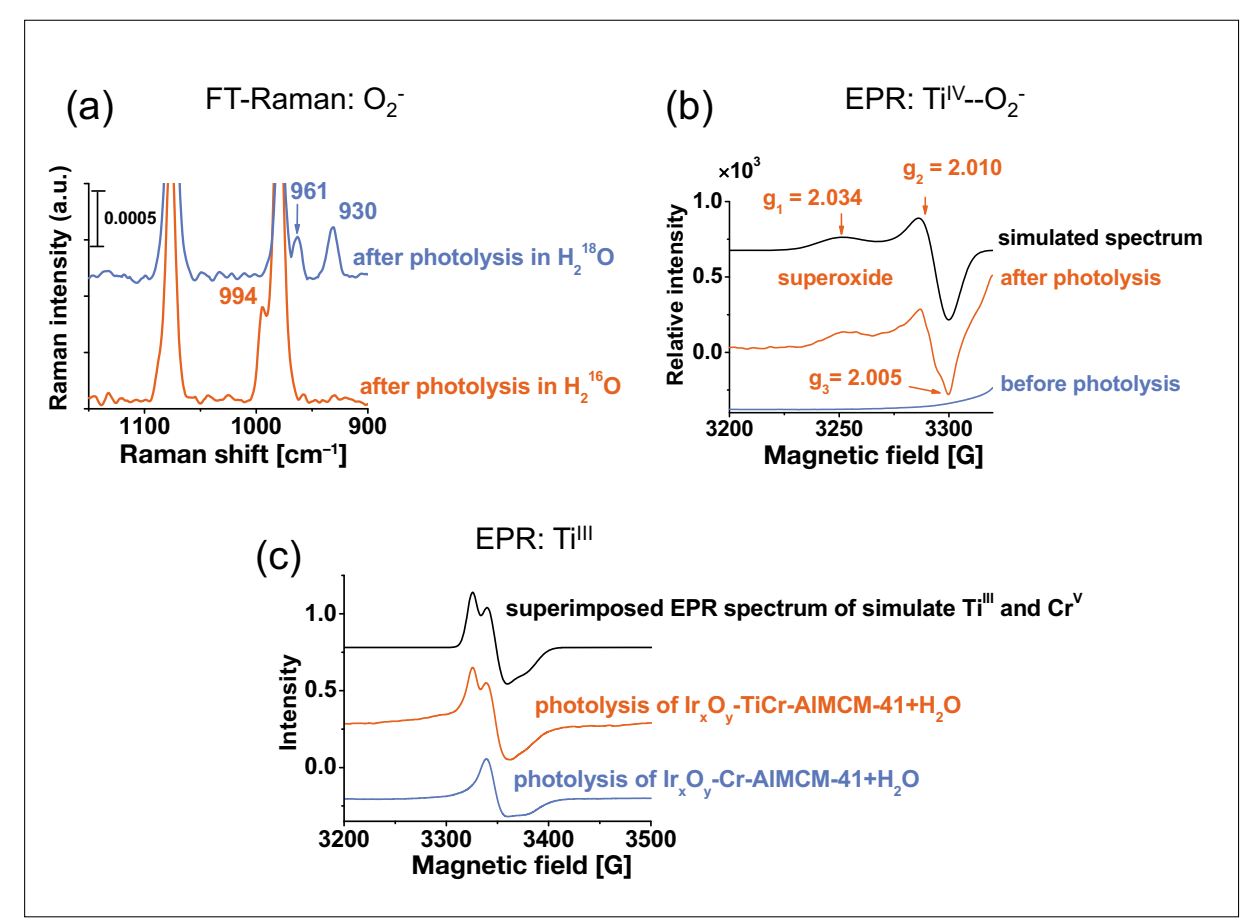

Fig. 10. Water oxidation at TiOCr'II-IrO $\mathrm{I}_{2}$ photocatalyst in aqueous solution. (a) FT-Raman spectra show the formation of $\mathrm{O}_{2}^{-}$(superoxide) in $\mathrm{H}_{2}{ }^{16} \mathrm{O}$ and $\mathrm{H}_{2}^{18} \mathrm{O}$. (b) EPR signal of $\mathrm{Ti}^{1 \mathrm{~V}}-\mathrm{O}_{2}^{-}$complex formed during visible light-driven water oxidation. (c) EPR spectrum recorded upon irradiation of the photocatalyst in the absence of persulfate acceptor, leading to accumulation of Till. Simulated spectra corroborate interpretation of spectra. ${ }^{[30]}$ 
troscopic study of visible light-induced electron transfer between the $\mathrm{Mn}_{2} \mathrm{O}_{2}$ core of a di- $\mu$-oxo-bridged dinuclear Mn complex ((bpy) $)_{2} \mathrm{Mn}^{\mathrm{III}}(\mu-\mathrm{O})_{2} \mathrm{Mn}^{\mathrm{IV}}(\mathrm{bpy})_{2}$, bpy $=$ bipyridyl) and a $\mathrm{Cr}^{\mathrm{VI}}$ chromophore inside nanoporous silica (Fig. 11). Tetrahedral $\mathrm{Cr}^{\mathrm{VI}}$ centers on silica nanopore surfaces have a $\mathrm{Cr}^{\mathrm{VI}}-\mathrm{O}^{\mathrm{II}} \rightarrow \mathrm{Cr}^{\mathrm{V}}-\mathrm{O}^{\mathrm{I}}$ ligand-to-metal charge-transfer chromophore that absorbs in the blue and green spectral region. ${ }^{[31]}$

EXAFS spectroscopy of the Mn Kedge confirms that the structure of $\mathrm{Mn}$ dimer core and the ligand sphere is not perturbed upon loading of the complex into the channels of MCM-41 silica (Fig. 11). Furthermore, the Cr K-edge EXAFS spectrum shows no second nearest neighbor signal that would indicate the formation of a covalent linkage between the $\mathrm{Cr}^{\mathrm{VI}}$ chromophore and the Mn dimer complex. Likewise, the intensity of the characteristic 16-line EPR signal of the $\mathrm{Mn}^{\mathrm{III}}(\mu-\mathrm{O})_{2} \mathrm{Mn}^{\mathrm{IV}}$ core does not change upon loading of the complex, which shows that the integrity of the oxidation state is preserved inside the silica pores. ${ }^{[41]}$

In situ FT-Raman, EPR and X-ray monitoring allowed us to detect visible lightinduced electron transfer between the $\mathrm{Mn}$ dimer core and the $\mathrm{Cr}$ chromophore, with all initial and final states of the process spectroscopically identified. ${ }^{[41]}$ As shown in Fig. 12C, excitation of the $\mathrm{Cr}^{\mathrm{VI}}-\mathrm{O}^{\mathrm{II}} \rightarrow$ $\mathrm{Cr}^{\mathrm{V}}-\mathrm{O}^{\mathrm{I}}$ ligand-to-metal charge-transfer chromophore with blue light $(460 \mathrm{~nm})$ resulted in decrease of a Mn-O stretch band of $\mathrm{Mn}^{\mathrm{III}} \mathrm{Mn}^{\mathrm{IV}}$ at $700 \mathrm{~cm}^{-1}$ under concurrent rise of $\mathrm{Mn}^{\mathrm{IV}} \mathrm{Mn}^{\mathrm{IV}}$ absorption at $645 \mathrm{~cm}^{-1}$. The oxidation of $\mathrm{Mn}^{\mathrm{III}} \mathrm{Mn}^{\mathrm{IV}}$ is also seen by decrease of the 16-line EPR signal (Fig. $12 \mathrm{~A}, \mathrm{~B})\left(\mathrm{Mn}^{\mathrm{IV}} \mathrm{Mn}^{\mathrm{IV}}\right.$ is EPR silent), while oxidation to $\mathrm{Mn}^{\mathrm{IV}} \mathrm{Mn}^{\mathrm{IV}}$ is confirmed by an $1 \mathrm{eV}$ blue shift of the Mn K-edge. ${ }^{[41]}$ At the same time, $\mathrm{Cr}^{\mathrm{VI}}$ is decreasing (loss of the sym $\mathrm{O}=\mathrm{Cr}^{\mathrm{VI}}=\mathrm{O}$ stretch at $895 \mathrm{~cm}^{-1}$ in the FT-Raman spectrum) while the $\mathrm{Cr}^{\mathrm{V}} \mathrm{EPR}$ signal grows in. This is the first observation of visible light-driven oxidation of a dinuclear $\mathrm{Mn}$ complex to the $\mathrm{Mn}^{\mathrm{IV}} \mathrm{Mn}^{\mathrm{IV}}$ oxidation state $\left(\mathrm{Cr}^{\mathrm{VI}}+\mathrm{Mn}^{\mathrm{III}} \mathrm{Mn}^{\mathrm{IV}} \rightarrow \mathrm{Cr}^{\mathrm{V}}+\right.$ $\left.\mathrm{Mn}^{\mathrm{IV}} \mathrm{Mn}^{\mathrm{IV}}\right)$, which is endoergic by $0.61 \mathrm{~V}$. A factor that may contribute to the long lifetime for the charge separation (up to several minutes at room temperature) is the large reorganization energy associated with $\mathrm{Cr}^{\mathrm{VI}}$ to $\mathrm{Cr}^{\mathrm{V}}$ reduction; the short $\mathrm{Cr}=\mathrm{O}$ double bond is replaced by the $0.4 \mathrm{~A}$ longer $\mathrm{Cr}-\mathrm{O}$ single bond ${ }^{[18]}$, which will slow down the back reaction. Particularly revealing is the finding that charge transport between components in a nanoporous silica scaffold proceeds with reasonable efficiency even in the absence of a covalent linkage. The nanometer distance imposed by the nanopore environment appears sufficient for achieving efficient photo-induced electron transport between chromophore and catalyst.

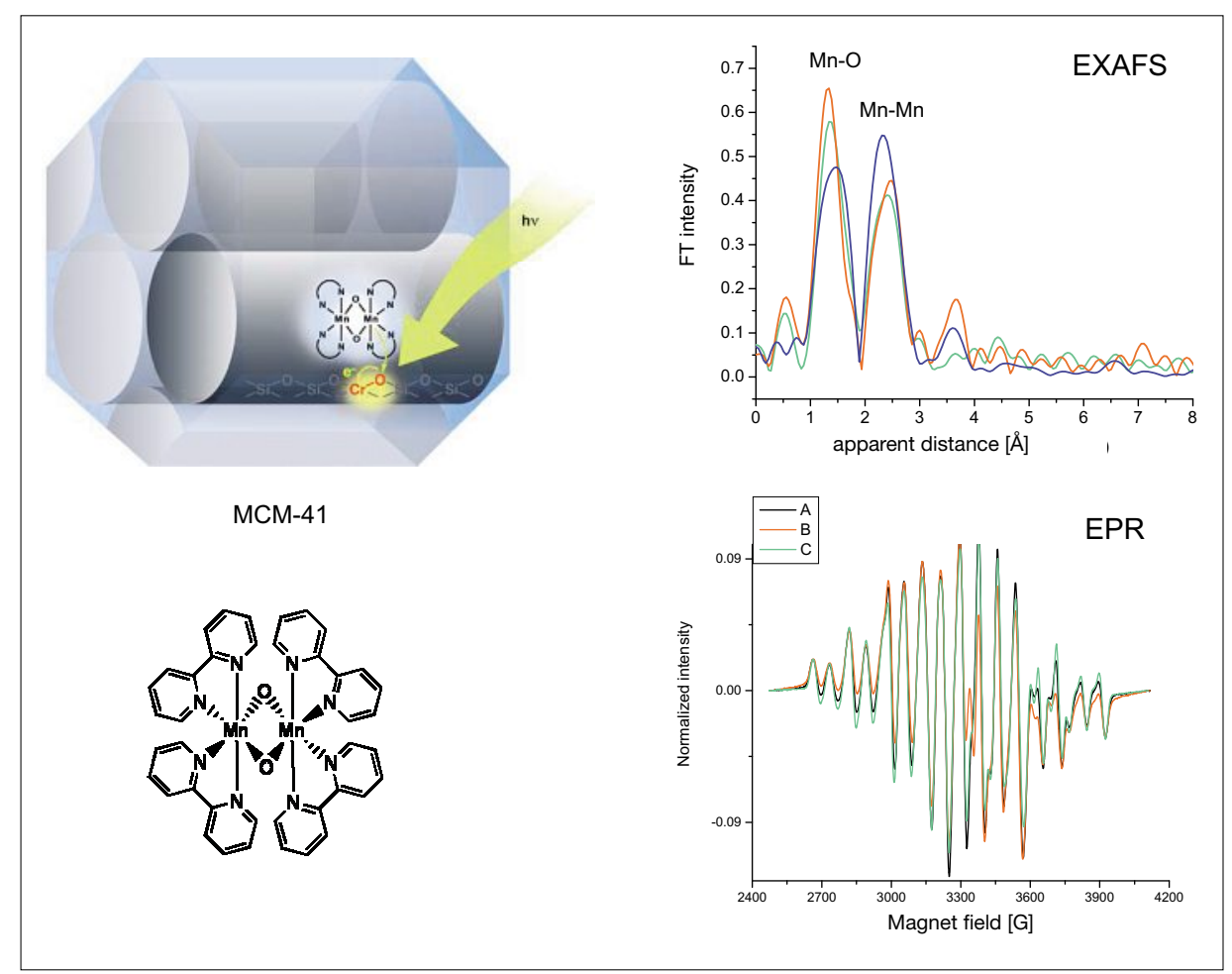

Fig. 11. Structural model of $M n$ dimer water oxidation catalyst $(b p y)_{2} M n^{\prime \prime \prime}(\mu-O)_{2} M n^{\prime v}(b p y)_{2}$, bpy $=$ bipyridyl loaded into MCM-41 silica support. EXAFS and EPR spectra demonstrate retention of structural and electronic integrity. EXAFS: Black, crystalline compound; red, complex loaded into MCM-41; green, complex loaded into Cr-MCM-41. EPR: Black, complex loaded into MCM-41; red, complex loaded into Cr-MCM-41; green, complex in acetonitrile solution.

\subsection{Efficient Water Oxidation Catalyst Made of Earth Abundant Material}

The polynuclear $\mathrm{TiOCr}^{\mathrm{III}}-\mathrm{IrO}_{2}$ unit presented above is not only a robust but already a reasonably efficient photocatalyst for water oxidation under visible light. In fact, as a multi-electron water oxidation catalyst, Ir oxide easily fulfills the rate requirements for keeping up with the solar flux. Yet, as it is the least abundant element on earth, Ir is not suitable for use on a large scale. Therefore, exploration of multi-electron catalysts based on oxides of the much more abundant first row transition metals is imperative. In fact, oxides of metals like $\mathrm{Co}$ and $\mathrm{Mn}$ are known to exhibit catalytic activity for water oxidation when used as anode coatings in electrochemical cells. ${ }^{[32]}$ Electrodeposits on anodes generated from Co phosphate solution were recently found to form a durable oxygen-evolving catalyst that operates at neutral $\mathrm{pH}$ and with modest overpotential.[42] Si-doped nanostructured $\mathrm{Fe}_{2} \mathrm{O}_{3}$ topped by a Co oxide monolayer as photocatalytic anode material was reported to give high incident photon to current efficiency in photoelectrochemical water oxidation. ${ }^{[43]}$ Oxygen evolution was also observed from aqueous suspensions of micrometer-sized Co or Mn oxide particles using a chemical oxidant, generated either photochemically or directly added to the solution, to drive the catalyst. ${ }^{[37]}$ Taken together, the previous works suggest that these abundant metal oxides might form robust, efficient nanometer-sized catalysts for water oxidation if very large surface area, nanostructured forms with highly active surface sites can be developed.

Using wet impregnation $\left(\mathrm{Co}\left(\mathrm{NO}_{3}\right)_{2}\right.$ in ethanol, 4wt \% loading) followed by controlled calcination, we prepared $35 \mathrm{~nm}$ size $\mathrm{Co}_{3} \mathrm{O}_{4}$ clusters consisting of parallel bundles of nanorods ( $8 \mathrm{~nm}$ diameter) interconnected by short bridges inside the pores of SBA-15 silica support, shown in Fig. 13A. ${ }^{[44]}$ Close inspection of the TEM images of the clusters inside the silica scaffold and in bare form (after removal of the silica scaffold by edging, Fig. 13A(c)), show that the nanorod bundles are exact replica of the SBA-15 mesopore structure (nanorod bundles have spheroid shape with a short diameter of $35 \mathrm{~nm}$ and a long diameter of 65 $\mathrm{nm})$. XRD and EXAFS spectra confirmed the spinel structure of the $\mathrm{Co}_{3} \mathrm{O}_{4}$ catalysts (Fig.13B). Suspension of the mesoporous silica particles containing $\mathrm{Co}_{3} \mathrm{O}_{4}$ clusters in aqueous solution ( $\mathrm{pH} 5.8$, room temperature) and driving the catalyst by visible light-generated $\mathrm{Ru}^{+3}(\mathrm{bpy})_{3}$ species (a standard technique for comparing efficiencies of various water oxidation catalysts ${ }^{[37]}$ ) resulted in rapid evolution of $\mathrm{O}_{2}$ in the headspace of the aqueous solution. Mass spectrometric monitoring, shown in Fig. $13 \mathrm{C} \& \mathrm{D}$ indicated that $\mathrm{O}_{2}$ evolution was 


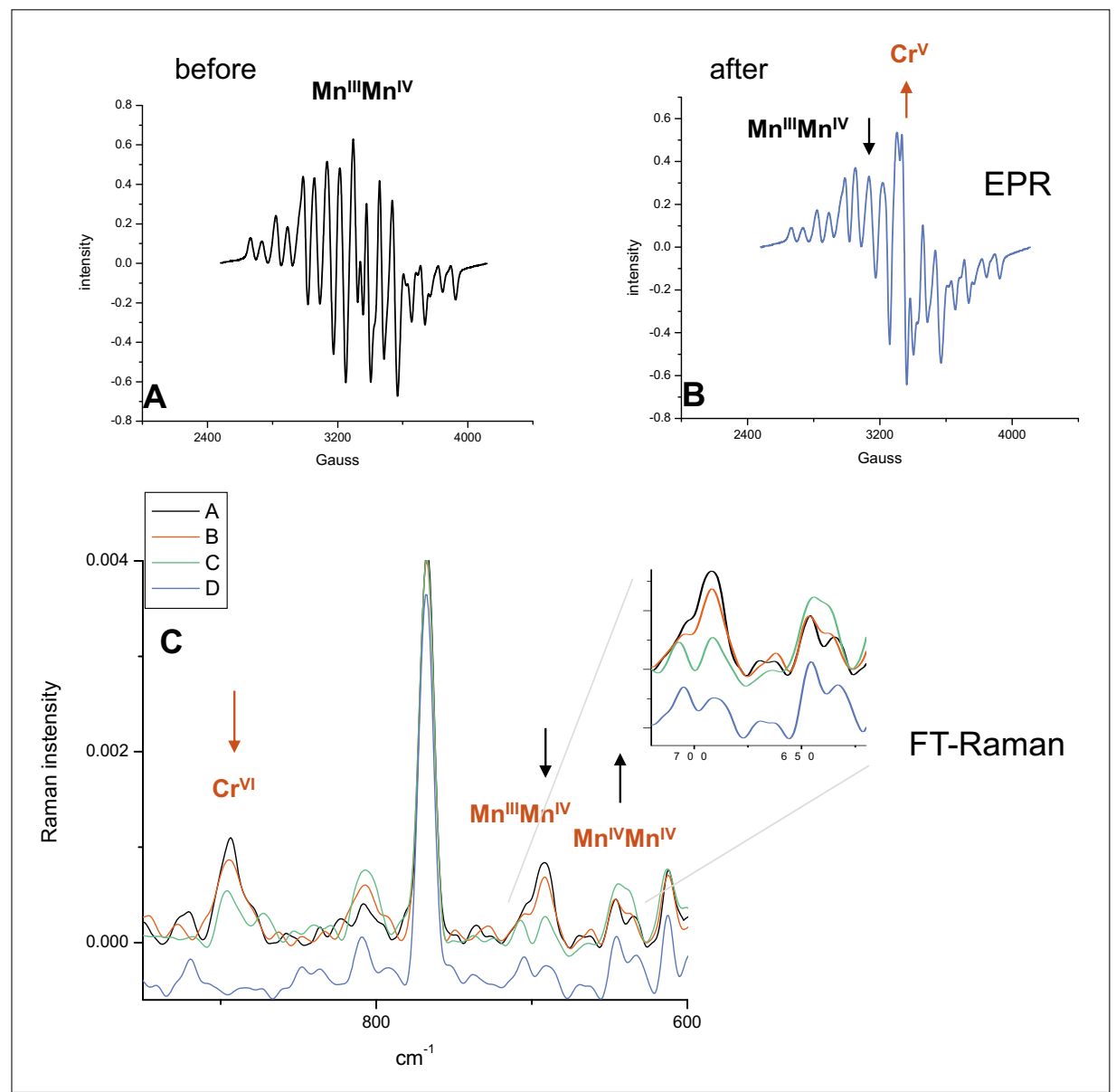

Fig. 12. Visible light-induced electron transfer between $\mathrm{Mn}$ dimer core and $\mathrm{Cr}$ chromophore. (A) and (B): EPR signal before and after visible light illumination of $\mathrm{Cr}-\mathrm{MCM}-41$ loaded with (bpy) ${ }_{2} \mathrm{Mn}^{\mathrm{II}}(\mu-\mathrm{O})_{2} \mathrm{Mn}^{\mathrm{IV}}(\mathrm{bpy})_{2}$. (C) FT-Raman spectra recorded upon illumination with visible light for $5 \mathrm{~min}$ (red) and $30 \mathrm{~min}$ (green).
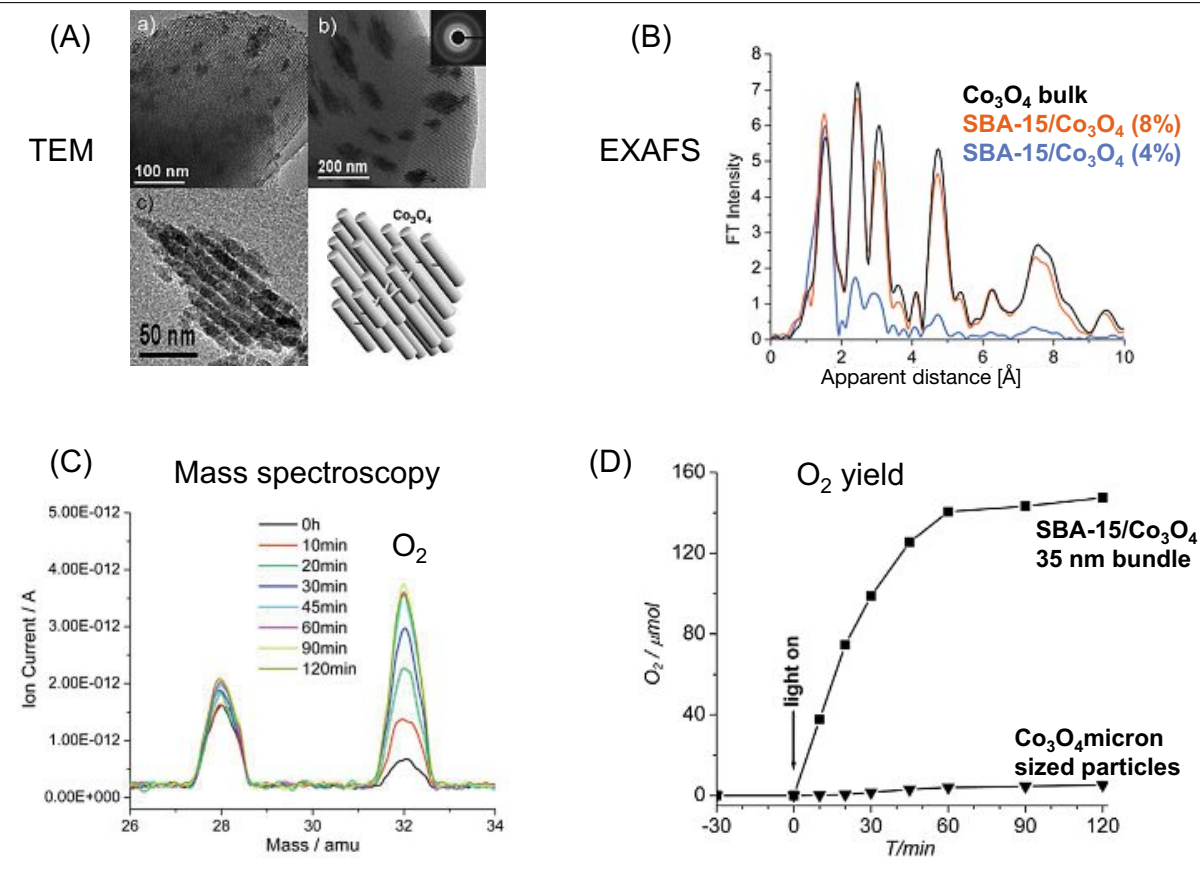

Fig. 13. $\mathrm{Co}_{3} \mathrm{O}_{4}$ nanocluster catalyst for water oxidation in SBA-15 silica support. (A) TEM images of (a) SBA-15/ $\mathrm{Co}_{3} \mathrm{O}_{4} 4 \%$ loading. (b) $8 \%$ loading. (c) $\mathrm{Co}_{3} \mathrm{O}_{4}$ nanocluster ( $8 \%$ ) after removal of the SBA-15 silica material using aqueous $\mathrm{NaOH}$ as edging agent. (B) EXAFS spectra for SBA-15/ $\mathrm{Co}_{3} \mathrm{O}_{4}$ samples and comparison with bulk $\mathrm{Co}_{3} \mathrm{O}_{4}$. (C) and (D): Mass spectrometric monitoring of visible light driven oxygen evolution of $\mathrm{SBA}-15 / \mathrm{Co}_{3} \mathrm{O}_{4}(4 \%)$ aqueous suspension, and comparison with $\mathrm{Co}_{3} \mathrm{O}_{4}$ micron sized particle suspension. linear during the first 20 minutes and then leveled off after one hour due to consumption of the persulfate acceptor but resumed at the initial rate when adding fresh $\mathrm{S}_{2} \mathrm{O}_{8}^{-2}$ acceptor. From these measurements, a turnover frequency of $1140 \mathrm{~s}^{-1}$ per $\mathrm{Co}_{3} \mathrm{O}_{4}$ cluster was calculated (TOF, number of oxygen molecules per second per nanocluster) under mild conditions ( $\mathrm{pH} \mathrm{5.8,22}{ }^{\circ} \mathrm{C}$, overpotential $350 \mathrm{mV}^{[44]}$ ). Oxygen evolution at these nanostructured $\mathrm{Co}_{3} \mathrm{O}_{4}$ clusters in mesoporous silica constitutes the first observation of efficient water oxidation by a nanometer-sized multi-electron catalyst made of an abundant transition metal oxide.

Comparison of the rates of $\mathrm{O}_{2}$ production of nanostructured catalyst clusters and micron-sized $\mathrm{Co}_{3} \mathrm{O}_{4}$ particles (Fig. 13D), normalized to equal weight, furnishes insight into the factors responsible for the high catalytic efficiency. The nanoclusters are 1550 times more efficient than the micron-sized particles. ${ }^{[44]}$ The largest contribution, namely a factor of 96 , is due to the much large surface area of the nanostructured cluster. Another factor of 16 reflects a higher activity of Co surface sites in the case of the nanocluster, very likely caused by the steeply curved nanorod surface and/ or a synergistic effect of the Co oxide surface interacting with the silica wall environment. Taking the geometrical projection of the $35 \mathrm{~nm}$ diameter bundle of nanorods onto a plane, a TOF of $1 \mathrm{O}_{2}$ molecule $\mathrm{s}^{-1} \mathrm{~nm}^{-2}$ is calculated. Therefore, a stack of one hundred of these $\mathrm{Co}_{3} \mathrm{O}_{4}$ clusters in a nanoporous silica scaffold would meet the required TOF of $100 \mathrm{~s}^{-1} \mathrm{~nm}^{-2}$ to keep up with the solar flux. The high rate, mild $\mathrm{pH}$ and temperature conditions, modest overpotential, robustness and abundance of the material make this a promising catalyst for water oxidation in solar fuel generating systems.

While we focus here on metal oxide nanoclusters as multi-electron catalysts, another interesting recent development in the area of all-inorganic structures are polyoxometallate-based $\mathrm{O}_{2}$ evolving catalysts. ${ }^{[45,46]}$

\section{Closing the Photocatalytic Cycle}

A crucial property of photocatalytic units made of a binuclear charge-transfer chromophore coupled to a multi-electron catalyst is the flexibility in selecting donor and acceptor metal center and oxidation state. The modular nature of the units enables optimal redox level matching, tuning of visible light absorption characteristics, and efficient electronic coupling, all of which are critical for coupling the components with minimal loss of energy or charge. The ability to carefully select 
the redox potential of donor and acceptor center of an MMCT chromophore is also particularly important for closing the photocatalytic cycle by driving the $\mathrm{CO}_{2}$ reduction with electrons generated by the water oxidation reaction. In order to accomplish directional electron transport from the water oxidation site to the $\mathrm{CO}_{2}$ reduction photocatalyst with minimum loss of energy, the redox potentials of the two photocatalytic sites need again to be carefully matched. The selective methods for assembling binuclear chromophores and metal oxide nanocluster catalysts in silica nanopores offer a new approach for addressing this long standing challenge of artificial photosynthesis.

A critical step in assembling an integrated solar fuel conversion system is to couple the photocatalytic units for $\mathrm{H}_{2} \mathrm{O}$ oxidation and $\mathrm{CO}_{2}$ reduction across a physical barrier that separates the two half reactions. A nanoscale silica wall has the desired properties because it transmits protons fast on the time scale of catalytic turnover yet is impermeable to small molecules like $\mathrm{O}_{2}$. Hence, the material may act as a membrane for separating reduction and oxidation sites if methods can be developed for establishing electron transport between the binuclear chromophores. We are currently developing nanoscale silica walls penetrated by nanowires for electron transport between the photocatalytic oxidation and reduction units. Coupling across the silica membrane will close the photocatalytic cycle and allow generation of $\mathrm{O}_{2}$ and reduced $\mathrm{CO}_{2}$ products in separate physical spaces.

\section{Conclusions}

All-inorganic photocatalytic units for water oxidation and carbon dioxide reduction in nanoporous silica scaffolds offer a new approach for developing robust artificial photosynthetic systems. With a design consisting of a binuclear charge-transfer unit as single photon - single electron pump driving a multi-electron transfer catalyst, efficiency issues associated with the synchronization of light absorption and chemical transformation are minimized. Most importantly, the free choice of donor and acceptor metal centers made possible by flexible synthetic methods allows us to match redox potentials of the components for maximum solar coverage and photon to chemical energy conversion efficiency, and facilitates the use of abundant materials.

With proof of concept for polynuclear photocatalytic units for water oxidation and carbon dioxide reduction established by the recent work discussed here, future effort will focus on improving conversion efficiencies and demonstrating the cou- pling of the half reactions under separation of the products in an integrated system. Rapid expansion of nanostructured materials and methods to functionalize them, combined with structural and mechanistic tools provided by advanced spectroscopy and imaging makes this a particularly promising time to reach for the goal of efficient generation of a fuel by sunlight.

\section{Acknowledgement}

This work was supported by the Director, Office of Science, Office of Basic Energy Sciences, Division of Chemical, Geological and Biosciences of the U.S. Department of Energy under Contract No. DE-AC02-05CH11231. I am indebted to current and recent postdoctoral fellows whose work is discussed in this review and whose names are given in the references. I thank Dr. Vittal Yachandra and his group for access to the EPR laboratory and for help with EXAFS experiments and analysis.

Received: October 1, 2009

[1] N. S. Lewis, D. G. Nocera, Proc. Natl. Acad. Sci. USA 2006, 103, 15729.

[2] A. Fujishima, K. Honda, Nature 1972, 238, 37.

[3] M. S. Wrighton, A. B. Ellis, P. T. Wolczanski, D. L. Morse, H. B. Abrahamson, D. S. Ginley, J. Am. Chem. Soc. 1976, 98, 2774.

[4] H. Kato, K. Asakura, A. Kudo, J. Am. Chem. Soc. 2003, 125, 3082.

[5] K. Maeda, K. Teramura, D. Lu. T. Takata, N. Saito, Y. Inoue, K. Domen, Nature 2006, 440, 295.

[6] M. Gratzel, Nature 2001, 414, 338.

[7] O. Khaselev, J. Turner, Science 1998, 280, 425.

[8] T. Inoue, A. Fujishima, S. Konishi, K. Honda, Nature 1979, 277, 637.

[9] J. C. Hemminger, R. Carr, G. A. Somorjai, Chem. Phys. Lett. 1978, 57, 100.

[10] F. Saladin, L. Forss, I. Kamber, J. Chem. Soc., Chem. Commun. 1995, 533.

[11] H. Fujiwara, H. Hosokawa, K. Murakoshi, Y. Wada, S. Yanagida, Langmuir 1998, 14, 5154.

[12] H. Yoneyama, Catal. Today 1997, 39, 169.

[13] A. L. Linsebigler, G. Lu, J. T. Yates, Jr., Chem. Rev. 1995, 95, 735.

[14] J. Yano, J. Kern, K. Sauer, M. J. Latimer, Y. Pushkar, J. Biesiadka, B. Loll, W. Saenger, J. Messinger, A. Zouni, V. K. Yachandra, Science 2006, 314, 821

[15] L. Sun, L. Hammarstrom, B. Akermark, S. Styring, Chem. Soc. Rev. 2001, 30, 36.

[16] W. Lin, H. Frei, J. Phys. Chem. B 2005, 109, 4929.

[17] J. S. Beck, J. C. Vartuli, W. J. Roth, M. E. Leonowics, C. T. Kresge, K. D. Schmitt, C. T. W. Chu, D. H. Olson, E. W. Sheppard, S. B. McCullen, J. B. Higgins, J. L. Schlenker, J. Am. Chem. Soc. 1992, 114, 10834.

[18] H. Han, H. Frei, J. Phys. Chem. C 2008, 112, 8391.

[19] W. Lin, H. Frei, J. Am. Chem. Soc. 2005, 127, 1610.

[20] W. Lin, H. Han, H. Frei, J. Phys. Chem. B 2004, $108,18269$.

[21] Y. H. Yeom, H. Frei, in 'In-situ Characterization of Catalysts', Ed. B. M. Weckhuysen, American Scientific Publisher, San Diego, 2004, p. 32.

[22] L. Andersen, H. Frei, J. Phys. Chem. B 2006, $110,22601$.

[23] H. Han, H. Frei, Microporous Mesoporous Mater. 2007, 103, 265.

[24] R. Nakamura, A. Okamoto, H. Osawa, H. Irie, K. Hashimoto, J. Am. Chem. Soc. 2007, 129, 9596.
[25] B. P. Macpherson, P. V. Bernhardt, A. Hauser, S. Pages, E. Vauthey, Inorg. Chem. 2005, 44, 5530, and references therein.

[26] G. Blasse, Struct. Bonding 1991, 76, 153.

[27] T. Cuk, W. W. Weare, H. Frei, to be submitted.

[28] D. Y. Zhao, J. L. Feng, Q. S. Huo, N. Melosh, G. H. Frederickson, B. F. Chmelka, G. D. Stucky, Science 1998, 279, 548

[29] A. Warshel, Proc. Natl. Acad. Sci. USA 1980, 77,3105 .

[30] H. Han, H. Frei, J. Phys. Chem C 2008, 112, 16156.

[31] R. Nakamura, H. Frei, J. Am. Chem. Soc. 2006, $128,10668$.

[32] S. Trassatti, Electrochim. Acta 1984, 29, 1503.

[33] M. Yagi, E. Tomita, S. Sakita, T. Kuwabara, K. Nagai, J. Phys. Chem. B 2005, 109, 21489.

[34] J. Kiwi, M. Gratzel, Angew. Chem. Int. Ed. 1978, 17,860 .

[35] J. M. Lehn, J. P. Sauvage, R. Ziessel, Nouv. J. Chim. 1980, 4, 355.

[36] N. D. Morris, M. Suzuki, T. E. Mallouk, J. Phys. Chem. A 2004, 108, 9115.

[37] A. Harriman, I. J. Pickering, J. M. Thomas, P. A. Christensen, J. Chem. Soc., Faraday Trans. 1 1988, 84, 2795.

[38] W. J. Youngblood, S. H. Lee, Y. Kobayashi, E. A. Hernandez-Pagan, P. G. Hoertz, T. A. Moore, A. L. Moore, D. Gust, T. E. Mallouk, J. Am. Chem. Soc. 2009, 131, 926.

[39] H. Chen, R. Tagore, S. Das, C. Incarvito, J. W. Faller, R. H. Crabtree, G. W. Brudvig, Inorg. Chem. 2005, 44, 7661.

[40] W. Ruettinger, G. C. Dismukes, Chem. Rev. 1997, 97, 1.

[41] W. W. Weare, Y. Pushkar, V. K. Yachandra, H. Frei, J. Am. Chem. Soc. 2008, 130, 11355.

[42] M. W. Kanan, D. G. Nocera, Science 2008, 321, 1072.

[43] A. Kay, I. Cesar, M. Gratzel, J. Am. Chem. Soc. 2006, $128,15714$.

[44] F. Jiao, H. Frei, Angew. Chem. Int. Ed. 2009, 48, 1841.

[45] Y. V. Geletii, B. Bogdan, P. Kogerler, D. A. Hillesheim, D. G. Musaev, C. L. Hill, Angew. Chem. Int. Ed. 2008, 47, 3896.

[46] A. Sartorel, M. Carraro, G. Scorrano, R. De Zorzi, S. Geremia, N. D. McDaniel, S. Bernhard, M. Bonchio, J. Am. Chem. Soc. 2008, 130,5006 